\title{
Trends in Total and Extreme South American Rainfall in 1960-2000 and Links with Sea Surface Temperature
}

\author{
M. R. Haylock, ${ }^{\mathrm{a}}$ T. C. Peterson, ${ }^{\mathrm{b}}$ L. M. Alves, ${ }^{\mathrm{c}}{ }^{\text {T. }}$ Ambrizzi,${ }^{\mathrm{d}}{ }^{\mathrm{Y}}$ Y. M. T. Anunciação, ${ }^{\mathrm{e}} \mathrm{J}$. Baez, ${ }^{\mathrm{f}}$ \\ V. R. Barros, ${ }^{\mathrm{g}}$ M. A. Berlato, ${ }^{\mathrm{h}}{ }^{\mathrm{M}}$ M. Bidegain, ${ }^{\mathrm{i}}$ G. Coronel,${ }^{j}$ V. Corradi, ${ }^{\mathrm{k}}$ V. J. Garcia, ${ }^{\mathrm{l}}$ \\ A. M. Grimm, ${ }^{\mathrm{m}}$ D. Karoly, ${ }^{\mathrm{n}}$ J. A. Marengo, ${ }^{\mathrm{c}}$ M. B. Marino, ${ }^{\circ}$ D. F. Moncunill, ${ }^{\mathrm{p}}$ D. Nechet, ${ }^{\mathrm{q}}$ \\ J. Quintana, ${ }^{\mathrm{r}}$ E. Rebello, ${ }^{\mathrm{e}}$ M. Rusticucci, ${ }^{\mathrm{g}}$ J. L. Santos, ${ }^{\mathrm{s}}{ }^{\mathrm{I}}$. Trebejo, ${ }^{\mathrm{t}}$ And L. A. Vincent ${ }^{\mathrm{u}}$

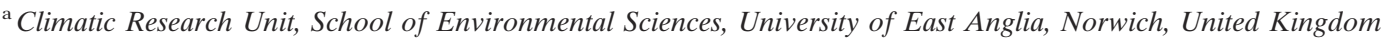 \\ ${ }^{\mathrm{b}}$ National Climatic Data Center, Asheville, North Carolina \\ ${ }^{\mathrm{c}}$ Centro de Previsão de Tempo e Estudos Climáticos, Instituto Nacional de Pesquisas Espaciais, Cachoeira Paulista, Brazil \\ ${ }^{\mathrm{d}}$ Universidade de São Paulo, São Paulo, Brazil \\ ${ }^{\mathrm{e}}$ Instituto Nacional de Meteorologia, Brasilia, Brazil \\ ${ }^{\mathrm{f}}$ Dirección Nacional de Meteorología e Hidrología, DINAC, Luquq, Paraguay \\ ${ }^{\mathrm{g}}$ Departamento de Ciencias de la Atmósfera y los Océanos, FCEN, Universidad de Buenos Aires, Buenos Aires, Argentina \\ ${ }^{\text {h } U n i v e r s i d a d e ~ F e d e r a l ~ d o ~ R i o ~ G r a n d e ~ d o ~ S u l, ~ P o r t ~ A l e g r e, ~ B r a z i l ~}$

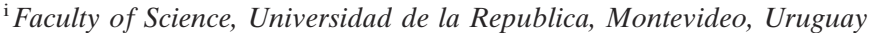 \\ ${ }^{\mathrm{j}}$ Universidad Nacional de Asunción, San Lorenzo, Paraguay \\ ${ }^{\mathrm{k}}$ Dirección Nacional de Meteorología, Montevideo, Uruguay \\ ${ }^{1}$ Universidad Nacional Agraria La Molina, La Molina, Peru \\ ${ }^{\mathrm{m}}$ Federal University of Parana, Curitiba, Brazil \\ ${ }^{\mathrm{n}}$ University of Oklahoma, Norman, Oklahoma \\ ${ }^{\circ}$ Banco Nacional De Datos, Servicio Meteorológico Nacional, Buenos Aires, Argentina \\ ${ }^{\mathrm{p}}$ Fundação Cearense de Meteorologia e Recursos Hídricos (FUNCEME), Fortaleza, Brazil \\ ${ }^{\mathrm{q}}$ Universidade Federal do Para, Belem, Brazil \\ ${ }^{\mathrm{r}}$ Dirección Meteorológica de Chile, Santiago, Chile \\ ${ }^{\mathrm{s}}$ Faculty of Marine Sciences, Escuela Superior Politécnica del Litoral, Guayaquil, Ecuador \\ ${ }^{\mathrm{t}}$ Servicio Nacional de Meteorología e Hidrología, Lima, Peru \\ ${ }^{u}$ Meteorological Service of Canada, Downsview, Ontario, Canada
}

(Manuscript received 26 January 2005, in final form 12 August 2005)

\begin{abstract}
A weeklong workshop in Brazil in August 2004 provided the opportunity for 28 scientists from southern South America to examine daily rainfall observations to determine changes in both total and extreme rainfall. Twelve annual indices of daily rainfall were calculated over the period 1960 to 2000, examining changes to both the entire distribution as well as the extremes. Maps of trends in the 12 rainfall indices showed large regions of coherent change, with many stations showing statistically significant changes in some of the indices. The pattern of trends for the extremes was generally the same as that for total annual rainfall, with a change to wetter conditions in Ecuador and northern Peru and the region of southern Brazil, Paraguay, Uruguay, and northern and central Argentina. A decrease was observed in southern Peru and southern Chile, with the latter showing significant decreases in many indices. A canonical correlation analysis between each of the indices and sea surface temperatures (SSTs) revealed two large-scale patterns that have contributed to the observed trends in the rainfall indices. A coupled pattern with ENSO-like SST loadings and rainfall loadings showing similarities with the pattern of the observed trend reveals that the change to a generally more negative Southern Oscillation index (SOI) has had an important effect on regional rainfall trends. A significant decrease in many of the rainfall indices at several stations in southern Chile and Argentina can be explained by a canonical pattern reflecting a weakening of the continental trough leading to a southward shift in storm tracks. This latter signal is a change that has been seen at similar latitudes in other parts of the Southern Hemisphere. A similar analysis was carried out for eastern Brazil using gridded indices calculated from 354 stations from the Global Historical Climatology Network (GHCN) database. The observed trend toward wetter conditions in the southwest and drier conditions in the northeast could again be explained by changes in ENSO.
\end{abstract}

Corresponding author address: Malcolm Haylock, Climatic Research Unit, University of East Anglia, Norwich NR4 7TJ, United Kingdom.

E-mail: M.Haylock@uea.ac.uk 


\section{Introduction}

Research into changes in rainfall extremes has seen an increase in published results in recent years since the Intergovernmental Panel on Climate Change (IPCC) Second Assessment Report (Nicholls et al. 1996) identified a scarcity of such studies. Studies from single countries have included a large part of the globe, including the United States (Karl and Knight 1998), Australia (Haylock and Nicholls 2000), the United Kingdom (Osborn et al. 2000), and single European countries, for example, Switzerland (Frei and Schar 2001), Italy (Brunetti et al. 2002), Norway (Benestad and Melsom 2002), and Belgium (Vaes et al. 2002). Crossborder regional studies are however less abundant, and the diverse nature of methods employed for the country-specific studies makes comparison between countries difficult.

The study by Plummer et al. (1999), who examined changes in climate extremes over Australia and New Zealand, was one of the earliest multicountry analyses. However it was Groisman et al. (1999) who attempted the first study of extreme rainfall for a globally diverse selection of countries. They examined extremes using gamma distribution statistical modeling for eight countries: Canada, the United States, Mexico, the former Soviet Union, China, Australia, Norway, and Poland. More recently work has been published by Klein Tank and Konnen (2003) and Haylock and Goodess (2004) examining trends and variability in extreme indices for almost all of Europe.

During the late 1990s, several international workshops developed indices for climate extremes (Folland et al. 1999; Nicholls and Murray 1999). The aim was to create a set of indices that could be calculated for a variety of climates to enable intercomparison between regions. Methodologies for calculating the indices were reported, highlighting that these indices should be designed to maximize their independence (low interindex correlation).

As well as a desire for more regional analyses, there was a need to include results from regions lacking in published studies. In particular developing countries were lacking analyses because of insufficient resources to undertake such analyses, limited access to data, fewer digitized records, and reduced data quality to which extremes analyses are very sensitive. Southeast Asia and the Pacific was identified as a key region (Manton and Nicholls 1999), in particular because of its vulnerability with regard to high population density, heightened rainfall variability due to ENSO, low-lying islands, coral reefs, and exposure to tropical cyclones. Therefore, in 1998 the Asia-Pacific Network (APN) for
Global Change Research funded a workshop on climate indices, and the results were published in Manton et al. (2001).

To tie together work on extremes for the IPCC Third Assessment Report, a near-global analysis was undertaken by Frich et al. (2002), who analyzed linear trends in 10 climate indices for a large part of North America, Europe, Asia, and the Pacific.

The Expert Team on Climate Change Detection, Monitoring and Indices (ETCCDMI; see http://www. clivar.org/organization/etccd/) was established as a joint venture of the World Meteorological Organization Commission for Climatology $(\mathrm{CCl})$ and the World Climate Research Program Climate Variability and Predictability (CLIVAR) program to provide advice on climate monitoring indices. Following the publication of Frich et al. (2002), the ETCCDMI identified key regions in which to promote climate change studies: the Caribbean, Central and South America, Africa, and west and central Asia. They decided the best way to establish research in these regions was through regional workshops similar in format to the APN workshop (Manton et al. 2001). In 2001 two such workshops were held: in Morocco to cover northern African countries (Easterling et al. 2003) and in Jamaica to cover the Caribbean (Peterson et al. 2002).

The ETCCDMI met again in 2003 to plan further workshops in time to produce results for the IPCC Fourth Assessment Report. Five workshops were planned for 2004, to take place in South Africa for southern African countries, in Brazil for southern South American countries, in Turkey for western Asian countries, in Guatemala for Central and northern South American countries and in India for central and south Asian countries. This paper deals with rainfall results from the Brazilian workshop. Temperature results are presented in the companion paper (Vincent et al. 2005).

The five-and-a-half-day Brazilian workshop was held in August 2004 in Maceio and was attended by 28 scientists from eight South American countries: Argentina, Bolivia, Brazil, Chile, Ecuador, Paraguay, Peru, and Uruguay. A new approach for this workshop was to invite a representative for each country from both a university and the national weather service. This was done in order to strengthen ties between the two groups as well as to promote research in both the educational and government streams. The key aims of the workshop were to provide a consistent methodology for analyzing extremes across the region; to establish a network of scientists with the hope of building on this in the future; and to provide capacity building to countries with less resources for climate change research. 
Until recently, there had been little published work on rainfall extremes in South America. As a result of the implementation of various projects on the ParanáLa Plata River Basin in southeastern South America, several recent papers have studied rainfall extremes in this basin and linked them to the regional circulation. Liebmann et al. (2004a) identified that extreme daily precipitation events in southeastern Brazil have a strong tendency to cluster in response to remote or local influences and that their occurrence is related to the frequency and intensity of the South American lowlevel jet (SALLJ) east of the Andes (Marengo et al. 2004). Intense/weak SALLJ episodes during the austral summer are related to enhanced/decreased moisture transport from the Amazon Basin and a larger/lower probability of extreme rainfall events in southeastern South America downstream of the jet. Previously, Carvalho et al. (2002) showed that most extreme events in the state of São Paulo in southeastern Brazil occur when the South Atlantic convergence zone (SACZ) is strong. Later, Carvalho et al. (2004) examined extreme precipitation events in relation to the Madden-Julian oscillation (MJO) and found that when convective activity linked to the MJO is weak over Indonesia, extreme rainfall events increase along the SACZ, including central eastern Brazil (and weaken in southeastern Brazil). They also concluded that extreme rainfall events in southeastern Brazil exhibit interannual variation related to large-scale forcing, with more days with extreme events during El Niño conditions than during La Niña. This is consistent with Grimm and Pscheidt (2001), who concluded that for southern Brazil there was a large increment in the frequency of extreme events during El Niño years in the 1963-92 period.

Previous studies have identified regional changes in total rainfall and links with sea surface temperatures (SSTs) and circulation. The late 1980s saw the earliest work directed at examining links between ENSO and South American rainfall. Studies by Aceituno (1988), Rogers (1988), and Ropelewski and Halpert (1987, 1989) identified a decrease in rainfall in northeast Brazil and an increase in southeast Brazil, northern Argentina, Paraguay, and Uruguay associated with El Niño events. The links between ENSO and rainfall in the Amazon Basin were examined by Marengo (1992), Marengo and Hastenrath (1993), and Marengo et al. (2001), who proposed a mechanism for the observed rainfall decrease during El Niño events. Two global studies (Dai et al. 1997; Dai and Wigley 2000) confirmed the ENSO precipitation response over South America by examining principal components of globally gridded annual rainfall. In particular, Dai and
Wigley (2000) included rainfall data over the oceans to show that the decrease in rainfall in northeast Brazil during an El Niño was part of a decrease across the entire tropical Atlantic. Similarly, the increase in southeast Brazil was connected with similar changes in the southeast Pacific. More recently the SACZ has received attention, with Liebmann et al. (1999) and Carvalho et al. (2002, 2004) examining ENSO-induced changes in its position and intensity and the effect of such changes on convective rainfall. These studies, along with Doyle and Barros (2002), highlight the importance of SSTs in the western South Atlantic in influencing the SACZ. The South American summer monsoon has received particular attention, as this season is generally the wettest period over most of the northern and central part of the continent. Vera et al. (2006), Nogues-Paegle et al. (2002), Grimm (2003, 2004), and Grimm et al. $(2000,1998)$ present a comprehensive account of findings for the South American monsoon and southern Brazil.

While there has been much attention given to variability and links with large-scale forcing, several recent studies have focused on the trends in total rainfall and rainfall extremes. In the Amazon Basin, observational studies based on time series of rainfall and river streamflow data (Chen et al. 2001; Chu et al. 1994; Depaiva and Clarke 1995; Gentry and Lopez-Parodi 1980; Marengo 2004; Marengo et al. 1998; Matsuyama et al. 2002) have produced conflicting results, showing positive or negative trends of rainfall mainly due to the use of different time periods. Marengo (2004) identifies a weak positive rainfall trend in the whole Amazonia, with negative/positive rainfall trends in northern/ southern section of the basin. He concludes that these trends are less important than the decadal-scale rainfall variability in both sides of the basin. Previously, Hastenrath and Greischar (1993) and Marengo et al. (1998) have found positive rainfall trends in northeast Brazil, while positive rainfall trends have been also detected in southern Brazil and northern Argentina (Barros et al. 2000).

Long-term trends in rainfall at stations in southern South America were examined by Minetti (1998) and Minetti et al. (2003). They found that for the period 1931-99 there had been a steady decrease in annual rainfall for a large area west of the Andes and an increase to the east in central Argentina. They identified a third region in northern Argentina that had seen a steady increase up until the 1980s when strong El Niño events caused a general decline. Similar trends were observed at some stations in southern South America by Rusticucci and Penalba (2000). They noted that the 
Chilean station Valdivia (used in this study) had seen a large decrease in total annual precipitation over the period 1901-90, mainly because of a decrease in winter precipitation. They suggested that this could be due to a change in the behavior of midlatitude frontal systems as had been found in Australia (Allan and Haylock 1993).

A recent study by Liebmann et al. (2004b) identified seasonal linear trends of precipitation from central South America during 1976-99 and showed that the largest positive trend occurred south of $20^{\circ} \mathrm{S}$ during January-March and centered over southern Brazil, while from 1948 to 1975 the trend is also positive, but with less than half the slope. The trend is due to an increase in the percent of rainy days, and an increase in the rainy day average. The precipitation trend is related to a positive sea surface temperature trend in the nearby Atlantic Ocean, but apparently not causally. The trend in the Atlantic seems to result from a decrease in mechanical stirring and coastal upwelling associated with a decrease in the strength of the western edge of the circulation associated with the South Atlantic High.

However, all these studies do not show any indication on trends in extreme rainfall events. Therefore, this paper attempts to provide updated information on rainfall trends in South America, both for mean and extreme events. Section 2 discusses the data availability and quality checking. Section 3 examines the linear trends in the rainfall indices. Section 4 looks at links with SSTs. In section 5 we analyze the precipitation indices from a large set of publicly available stations in eastern Brazil. Section 6 concludes the study.

\section{Data availability and quality}

The focus on climate indices derived from raw daily data overcame a major problem inherent in regional studies. The participating countries' fears of loss of control of daily data were allayed by the workshop format whereby participants brought data to be analyzed at the workshop but released only derived climate indices. While the climate indices are very valuable to scientists for climate monitoring, they are of little commercial value.

Participants were requested to bring at least five stations with daily rainfall and minimum and maximum temperature, as well as any available metadata for those stations. A long record was desirable from only high-quality climate stations covering as much of the country as possible.

Indices of extremes are sensitive to changes in station location, exposure, equipment, and observer practice.
Therefore, a large part of the workshop was devoted to testing stations for invalid measurements and inhomogeneities. First, negative rainfall amounts were set to missing and then a graph of the daily rainfall record was examined by eye. Outliers were considered more closely to see if they were part of a multiday wet spell and not the result of several days accumulation of missing observations, as is present in other regions, for example, Australia (Viney and Bates 2004). If a nearby station was available, then unusually high records could be compared across stations. Statistical tests were not used to identify outliers because of the large variety of distributions from which daily rainfall is derived in such a climatically diverse region.

A homogeneity test (Easterling and Peterson 1995) was applied to the annual total rainfall, although the lack of surrounding stations from which to construct a reference series made this difficult to interpret. Also the large interannual variability of annual rainfall, particularly in the ENSO-dominated dry regions of western South America, lead to the detection of significant jumps in the record that coincided with wet El Niño years. It was therefore decided to examine the annual climate indices by eye to identify unusual behavior possibly caused by changes to the station or observing practices. Stations with probable nonclimate-related changes were rejected. The homogeneity test was much more powerful in detecting jumps in the temperature record and is discussed further in a companion paper (Vincent et al. 2005).

Twelve rainfall indices were calculated and are listed in Table 1. Most of the indices relate to extreme rainfall, although two are more indicative of changes to the entire rainfall distribution: the total annual wet-day rainfall precipitation total (PRCPTOT) and the average wet-day rainfall intensity, the simple daily intensity index (SDII). A wet day refers to days with at least 1 $\mathrm{mm}$ of precipitation. This relatively high threshold was used as previous studies have found that lower thresholds can be sensitive to problems such as underreporting of small rainfall amounts and changes in the units of measurement (e.g., Hennessy et al. 1999).

In the workshops held prior to 2004, the data quality checking and calculation of indices was carried out using a Microsoft Excel spreadsheet "ClimDex." This platform was chosen due to its familiarity and ease of use. However a change to how some of the indices were calculated, in particular the use of bootstrapping for calculating the exceedence of base period normals (Zhang et al. 2005), meant that Excel was no longer the best program. Therefore a version of ClimDex was created using the powerful and statistically robust open 
TABLE 1. Rainfall indices with their definition and units. RR is the daily rainfall rate. A wet day has $\mathrm{RR} \geq 1 \mathrm{~mm}$. A dry day has $\mathrm{RR}<1 \mathrm{~mm}$. All indices are calculated annually from January to December.

\begin{tabular}{llll}
\hline \hline \multicolumn{1}{c}{ ID } & \multicolumn{1}{c}{ Indicator name } & \multicolumn{1}{c}{ Definitions } \\
\hline PRCPTOT & Wet-day precipitation & Annual total precipitation from wet days & Units \\
SDII & Simple daily intensity index & Average precipitation from wet days & Max number of consecutive dry days \\
CDD & Consecutive dry days & Max number of consecutive wet days & days \\
CWD & Consecutive wet days & Annual count of days when RR $\geq 10 \mathrm{~mm}$ & days \\
R10 mm & Heavy precipitation days & Annual count of days when RR $\geq 20 \mathrm{~mm}$ & days \\
R20 mm & Very heavy precipitation days & Annual total precipitation when RR $>$ 95th percentile of 1961-90 & mm \\
R95p & Very wet day precipitation & Annual total precipitation when RR $>$ 99th percentile of $1961-90$ & mm \\
R99p & Extremely wet day precipitation & mm \\
RX1day & Max 1-day precipitation & Annual max 1-day precipitation & mm \\
RX5day & Max 5-day precipitation & Annual max consecutive 5-day precipitation & $\%$ \\
R95pTOT & Very wet day proportion & Percentage of annual total precipitation from days with RR $\geq 95$ th & percentile of 1961-90 \\
& & Percentage of annual total precipitation from days with RR $\geq 99$ th & $\%$ \\
R99pTOT & Extremely wet day proportion & percentile of 1961-90 & \\
& & &
\end{tabular}

source "R" package (http://www.r-project.org). The new program "RClimDex" was provided with a graphical interface to run under a variety of operating systems. RClimDex is available for download from the ETCCDMI indices Web site (http://cccma.seos.uvic.ca/ ETCCDMI/).

After rejecting suspect stations, climate indices were calculated for an initial set of 68 stations. The climate indices are sensitive to missing data. Therefore the annual indices were not calculated for years where there were more than 15 days missing. The period of record for each station differed. Since it was desired to present results for a consistent period across the network, a methodology was adopted to find the best period and station set. The aim was to maximize the period length as well as the number of stations. Therefore for each period of at least $30 \mathrm{yr}$ from 1950 to 2003, the number of stations with at least $80 \%$ nonmissing annual indices was calculated. Clearly the shorter the period chosen, the more stations would pass the test. Since the aim was to optimize the period length as well as the number of stations, for each period we calculated the function,

$$
\begin{aligned}
f(\text { start year, end year })= & (\text { number of stations with } \\
& >80 \% \text { data }) \times \text { period length. }
\end{aligned}
$$

This had its maximum value for the period 1960-2000 (41 yr) with 54 stations. In comparison, if we look for the maximum number of stations that passed in any $35-y r$ period we only gain an additional two stations.

A map of the final set of 54 stations is shown in Fig. 1 and the stations are listed in Table 2. The start and end years listed in Table 2 are those for which the data were available. In all analyses we have confined the period to be 1960-2000. Although there are large areas with no stations in parts of Brazil, coverage is still good over most of the region, including the southern tip of continent.

\section{Linear trends}

Although RClimDex produces plots of the indices with the linear least squares trend, it was decided that the generally non-Gaussian distributed indices required a more statistically robust methodology for trend esti-

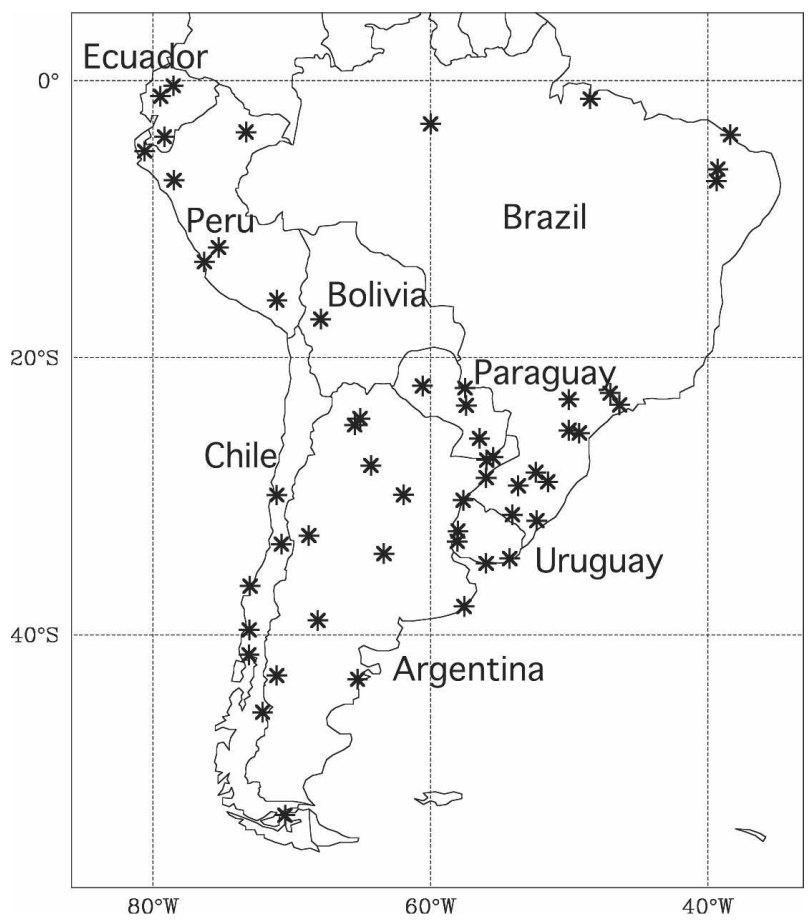

FIG. 1. Location of 54 rainfall stations. 
TABLE 2. Location, elevation, and period of data availability for 54 stations.

\begin{tabular}{|c|c|c|c|c|c|c|}
\hline Country & Station & Start & End & Lat & Lon & Elev (m) \\
\hline \multirow[t]{12}{*}{ Argentina } & Ceres & 1960 & 2002 & -29.88 & -61.95 & 88 \\
\hline & Esquel & 1959 & 2002 & -42.93 & -71.15 & 797 \\
\hline & Jujuy & 1960 & 2002 & -24.38 & -65.08 & 905 \\
\hline & Laboulage & 1960 & 2002 & -34.13 & -63.37 & 137 \\
\hline & Mar Del Plata & 1959 & 2002 & -37.93 & -57.58 & 21 \\
\hline & Mendoza & 1960 & 2002 & -32.83 & -68.78 & 704 \\
\hline & Monte Caseros & 1959 & 2002 & -30.27 & -57.65 & 54 \\
\hline & Neuquen & 1960 & 2002 & -38.95 & -68.13 & 271 \\
\hline & Posadas & 1959 & 2002 & -27.37 & -55.97 & 125 \\
\hline & Salta & 1959 & 2002 & -24.85 & -65.48 & 1221 \\
\hline & Santiago & 1959 & 2002 & -27.77 & -64.30 & 199 \\
\hline & Trelew & 1959 & 2002 & -43.20 & -65.27 & 43 \\
\hline Bolivia & Patacamaya & 1946 & 1999 & -17.20 & -67.92 & 3789 \\
\hline \multirow{16}{*}{ Brazil } & Aguafunda & 1933 & 2003 & -23.39 & -46.37 & 779 \\
\hline & Aquiraz & 1912 & 2001 & -3.90 & -38.38 & 14 \\
\hline & Bage & 1960 & 2000 & -31.33 & -54.11 & 214 \\
\hline & Belem & 1951 & 2000 & -1.46 & -48.48 & 10 \\
\hline & Cambara & 1959 & 2003 & -23.00 & -50.03 & 450 \\
\hline & Campinas & 1890 & 2004 & -22.54 & -47.05 & 694 \\
\hline & Crato & 1912 & 2001 & -7.22 & -39.38 & 412 \\
\hline & Curitiba & 1961 & 2003 & -25.43 & -49.28 & 910 \\
\hline & Iguatu & 1912 & 2001 & -6.37 & -39.30 & 216 \\
\hline & Julio Castilhos & 1957 & 1999 & -29.23 & -53.68 & 514 \\
\hline & Manaus & 1954 & 1999 & -3.13 & -59.96 & 67 \\
\hline & Passo Fundo & 1950 & 2000 & -28.26 & -52.41 & 687 \\
\hline & Pelotas & 1950 & 2000 & -31.75 & -52.35 & 7 \\
\hline & Ponta Grossa & 1954 & 2001 & -25.23 & -50.03 & 880 \\
\hline & Säo Borja & 1957 & 2000 & -28.66 & -56.00 & 99 \\
\hline & Veranopolis & 1957 & 1998 & -28.94 & -51.55 & 705 \\
\hline \multirow[t]{7}{*}{ Chile } & Concepcion & 1950 & 2003 & -36.46 & -73.02 & 11 \\
\hline & Coyahique & 1961 & 2003 & -45.58 & -72.12 & 310 \\
\hline & La Serena & 1950 & 2003 & -29.90 & -71.10 & 146 \\
\hline & Pta Arenas & 1953 & 2000 & -53.00 & -70.50 & 16 \\
\hline & Puerto Montt & 1950 & 2003 & -41.43 & -73.10 & 58 \\
\hline & Santiago & 1950 & 2003 & -33.45 & -70.76 & 520 \\
\hline & Valdivia & 1951 & 2003 & -39.63 & -73.08 & 19 \\
\hline \multirow[t]{3}{*}{ Ecuador } & Izobamba & 1966 & 2002 & -0.35 & -78.55 & 3058 \\
\hline & Loja & 1964 & 2000 & -4.04 & -79.20 & 2160 \\
\hline & Pichilingue & 1965 & 2002 & -1.11 & -79.48 & 120 \\
\hline \multirow[t]{5}{*}{ Paraguay } & Concepcion & 1959 & 1999 & -23.43 & -57.43 & 70 \\
\hline & Encarnacion & 1951 & 1999 & -27.17 & -55.50 & 85 \\
\hline & Mariscal & 1950 & 1999 & -22.02 & -60.59 & 165 \\
\hline & Pto Casado & 1947 & 1999 & -22.17 & -57.52 & 80 \\
\hline & Villarrica & 1956 & 1999 & -25.81 & -56.48 & 110 \\
\hline \multirow[t]{6}{*}{ Peru } & Canete & 1939 & 2001 & -13.07 & -76.32 & 158 \\
\hline & Huayao & 1952 & 2002 & -12.03 & -75.30 & 3308 \\
\hline & Imata & 1937 & 2002 & -15.83 & -71.08 & 4519 \\
\hline & Iquitos & 1957 & 1994 & -3.70 & -73.30 & 125 \\
\hline & Piura & 1956 & 1994 & -5.08 & -80.62 & 49 \\
\hline & Weberbauer & 1966 & 2003 & -7.17 & -78.50 & 2536 \\
\hline \multirow[t]{4}{*}{ Uruguay } & Carrasco & 1960 & 2000 & -34.83 & -56.00 & 33 \\
\hline & Mercedes & 1951 & 2000 & -33.25 & -58.07 & 17 \\
\hline & Paysandu & 1950 & 2000 & -32.50 & -58.03 & 61 \\
\hline & Rocha & 1950 & 2000 & -34.48 & -54.30 & 18 \\
\hline
\end{tabular}

mation. Also many of the indices contained much larger values for El Niño years, which would have undue influence on the nonresistant least squares method. Kendall's Tau was therefore adopted as a measure of the trend (Kendall 1938). This nonparametric statistic measures the relative ordering of all possible pairs of data points, where the year was used as the independent variable and the extreme index as the dependent 
variable. Kendall's Tau was used in preference to the Spearman correlation as the latter encounters problems with tied values, a situation that occurs often in the frequency-related indices. Kendall's Tau, expressed as a value between -1 and 1 , also has the added benefit that it enables comparison of indices between stations with vastly different rainfall amounts. In contrast, a map of least squares linear trends in rainfall would be dominated by the wetter stations.

Figure 2 shows the trends for the 12 rainfall indices. In this figure we have elected, for ease of interpretation, to show just the sign of the trend as well as flag stations with trends significant at $p<0.05$. Figure 2 shows there to be large regions of spatial coherence in the sign of the trends, as well as general agreement between the indices. Note that in all indices except the maximum consecutive dry days (CDD), an increase corresponds to wetter conditions. The pattern of trends in the PRCPTOT index shows broad features that are present to varying degrees in the other indices: I) generally wetter in the central eastern region (southern Brazil, Paraguay, Uruguay, and northeast Argentina); II) drier in the southwest (southern Chile and southwest Argentina); III) drier in southern Peru; and IV) wetter in northwest Peru and Ecuador. The southernmost station in Tierra del Fuego, Punta Arenas, Chile, has become significantly wetter. The stations in northern Brazil show no consistent sign. In all indices, the stations with a significant trend are located mainly in regions I and II. Punta Arenas also shows a significant trend in many indices. The positive trends in southern Brazil, Uruguay, and northeast Argentina agree with previous findings by Barros et al. (2000) and in central South America by Liebmann et al. (2004b) and Minetti et al. (2003).

There are several notable differences in the patterns of change between the indices and the general observations mentioned above. For Paraguay, although the sign of the trends of most of the indices agrees with those of the surrounding regions, the trends in CDD and the maximum consecutive wet days (CWD) are of the opposite sign. Therefore, although the rainfall has increased in intensity, the maximum wet/dry spell length has decreased/increased, although not significantly. This is also the case for the single Bolivian station, which shows an increase in all the indices (some significantly), except CWD. At most other stations the sign of CWD agrees with PRCPTOT and is opposite to CDD.

The patterns of trends for the frequency of extremes indices, R10 $\mathrm{mm}$ and $\mathrm{R} 20 \mathrm{~mm}$, are very similar to PRCPTOT. Several stations show a significant trend in the extremes but not in the total, for example, in Peru and Ecuador for R10 mm, but the reverse is also the case.

The two percentile exceedence indices, R95p and R99p, show similar patterns of trends to the total rainfall, although there are less significant changes in the area of increase in the central eastern region (region I). In this region more stations show a significant increase in the rainfall exceeding the 99th percentile than the 95th, including a significant decrease in R99p at a station in western Uruguay that showed a nonsignificant increase in total rainfall.

The two indices of maximum event intensity, RX1day and RX5day, show a less defined regional signal due to lower spatial coherence. No stations in region I show a significant trend and the trends here are of mixed sign. Several stations in the west show a significant change, although in several cases this is the opposite sign to PRCPTOT, for example, RX1day in central Peru and northern Chile. Also the stations in Ecuador show more of a nonsignificant decrease than the nonsignificant increase observed in PRCPTOT. The sign of the trends in the average intensity index, SDII, agrees mostly with PRCPTOT, although the significance is different for some stations.

The two indices of the proportion of total precipitation from extremes, R95pTOT and R99pTOT, both show a similar pattern of trends to PRCPTOT. There are more stations showing a significant change for the 99th percentile than for the 95th, particularly in region I.

One of the most consistent signals in Fig. 2 is the decrease in total and extreme rainfall in the southwest, as evident in the westernmost Argentinean station and its two neighboring Chilean stations. In all indices except CDD, these stations have showed a decrease, which in most cases is significant. These findings are consistent with previously discussed studies noting a rainfall decrease in this region (Minetti 1998; Minetti et al. 2003; Rusticucci and Penalba 2000).

With many stations showing significant trends in some of the indices, when averaged over larger areas the trends are significant in some regions. Figure 3 shows the time series of R20 mm averaged across all stations in the four quadrants of the continent when divided along $20^{\circ} \mathrm{S}$ and $61^{\circ} \mathrm{W}$. So as to weight each station equally we first normalized each station's time series to zero mean and unit variance. This figure shows a significant trend in the southeast quadrant covering southern Brazil, Paraguay, and Uruguay. For R99p (Fig. 4) there is a significant increase in this region also. Other than the southeast region, which has a significant trend in 6 of the 12 indices, the only other 

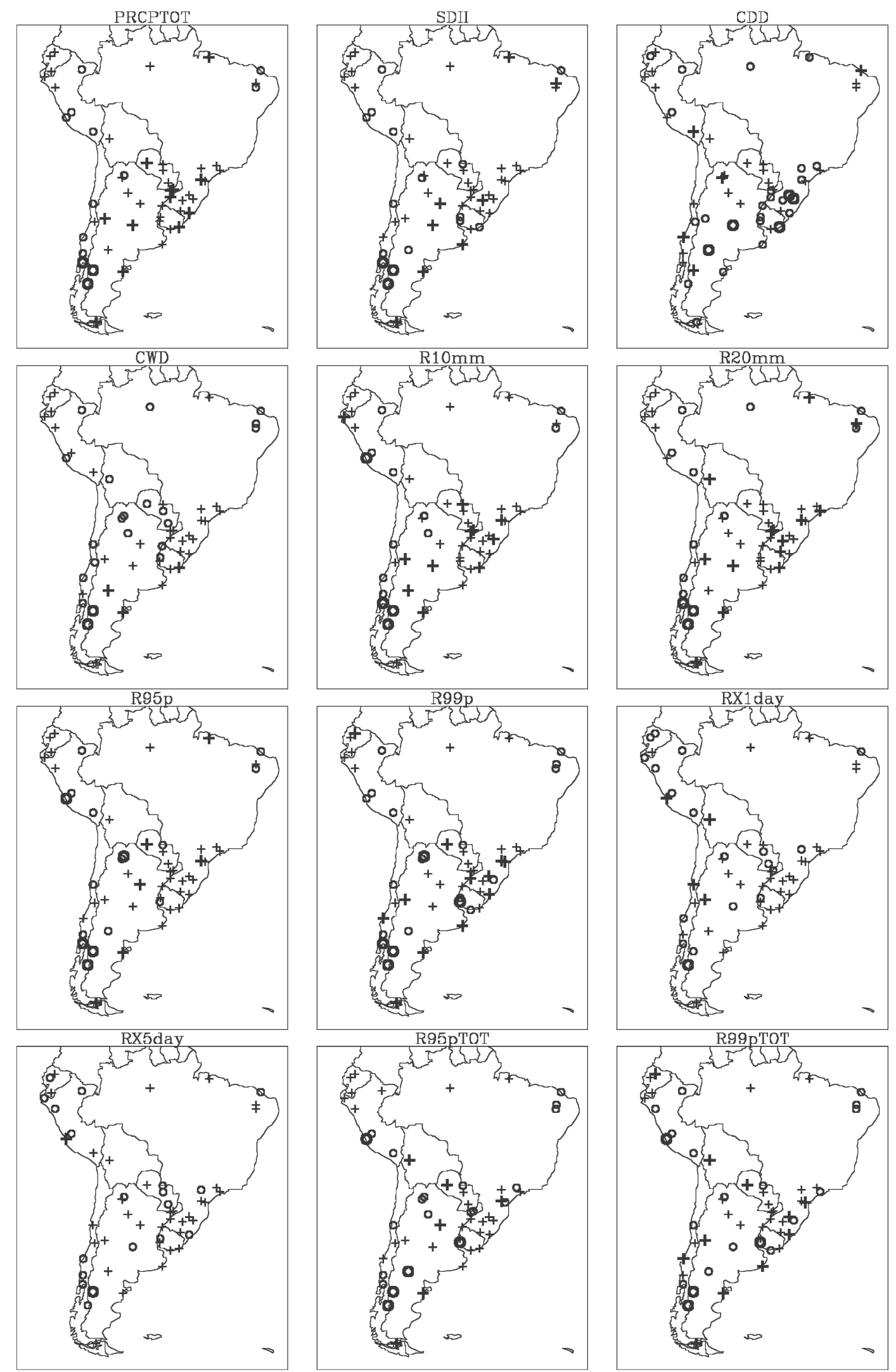

FIG. 2. Sign of the linear trend in rainfall indices as measured by Kendall's Tau. An increase is shown by a plus symbol, a decrease by a circle. Bold values indicate significant at $p<0.05$. 

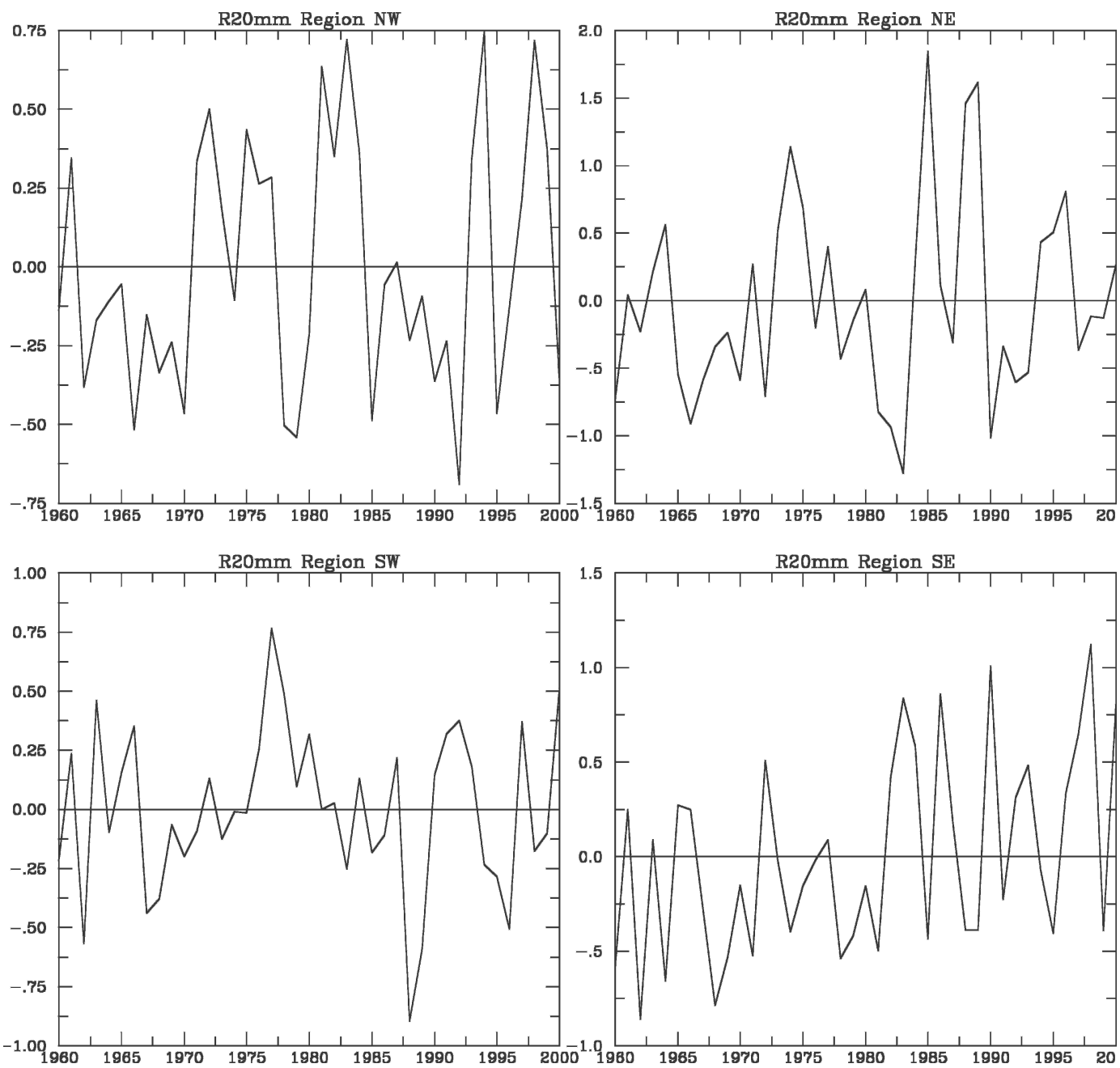

FIG. 3. Normalized number of days above $20 \mathrm{~mm}$ averaged across all stations in the four quadrants of the continent.

significant regional trend is for SDII in the northeast quadrant.

\section{Links with SST}

The high spatial coherence of the sign of the trends of the rainfall indices suggests that there could be changes to the large-scale forcing of the rainfall. This section examines possible changes in forcing.

The choice of predictors to examine is governed to a large extent by the time period over which the indices are calculated as well as the size of the region under examination. Although the rainfall indices are calculated annually, most of the indices are dominated by the rainfall during the wettest time of the year. However the diverse nature of the station network, which includes stations from the Tropics to the midhigh lati- tudes, means that the wet season occurs at different times of the year between stations. Therefore our potential predictor should be fairly constant throughout the year. The large area under consideration also dictates that our forcing variable should also be large scale. The most obvious candidate is the large-scale, slowly evolving SST anomalies.

We quantified the relationship between the rainfall indices and SSTs using a canonical correlation analysis (CCA). The canonical patterns and coefficients were calculated using a singular value decomposition (SVD) of the cross-covariance matrix of the principal components (PCs) of the two fields being examined. This is numerically more stable than the more common method of working with the joint variance-covariance matrix (Press et al. 1986) and also incorporates the prefiltering of the data by using just the significant PCs. 

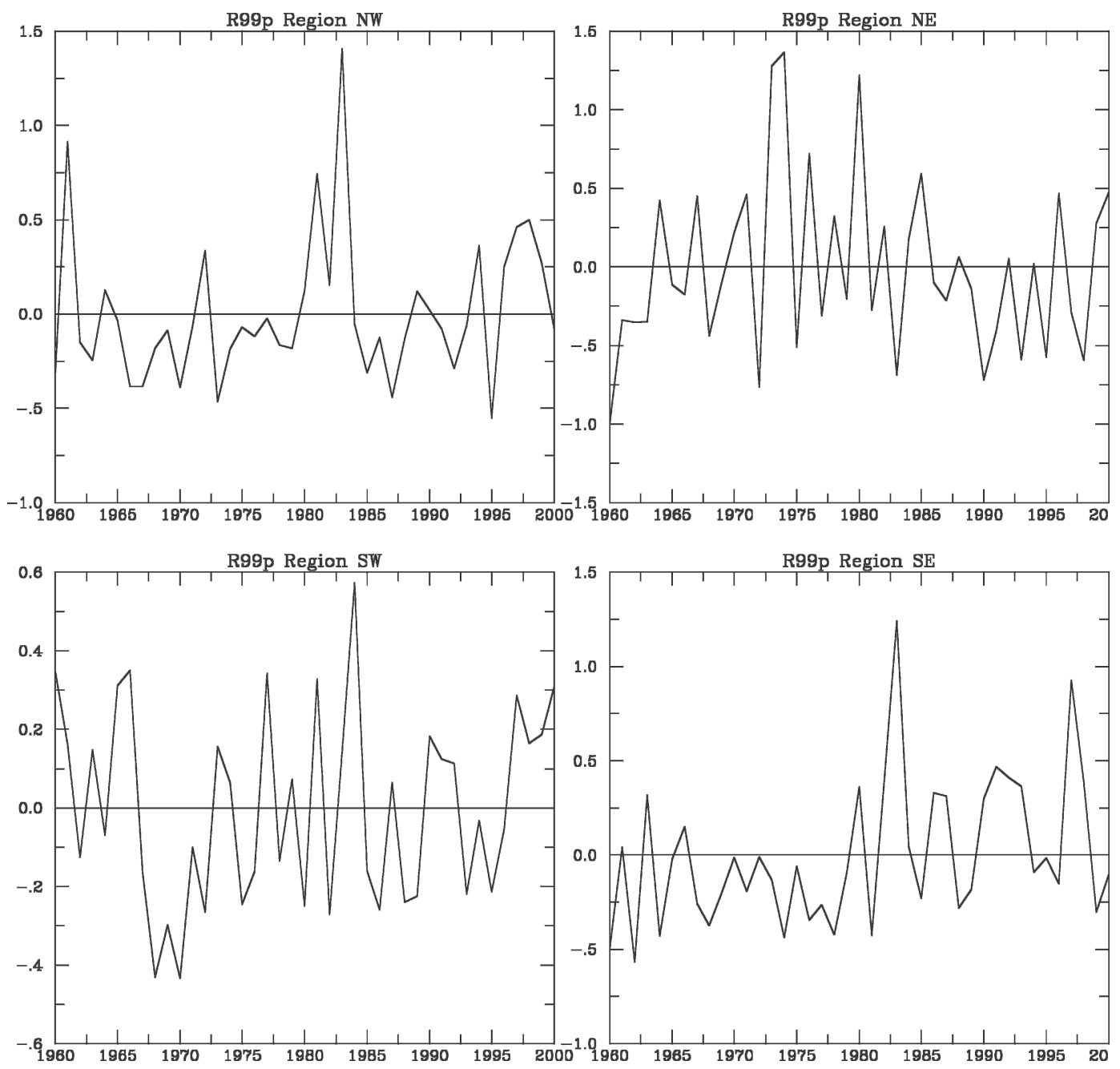

FIG. 4. Normalized 99th percentile of wet-day rainfall averaged across all stations in the four quadrants of the continent.

Bretherton et al. (1992) discuss the benefits of this methodology further and compare it with other methods of finding coupled modes.

This CCA methodology requires that we first find the number of significant PCs. This was objectively decided by a Monte Carlo process, whereby 1000 PC analyses were carried out using data randomly resampled in time from the stations (Preisendorfer et al. 1981). In each of the 1000 analyses, 54 station annual series of length 41 $\mathrm{yr}$ were generated with similar statistical properties to the original data but with random interstation correlations. Then, for each randomization, the eigenvalues were calculated. Each of the eigenvalues of the real observations was then compared against the distribution of the 1000 randomly generated values to determine whether they were greater than the rank 50 eigenvalue (equivalent to $p<0.05$ ). This methodology is the same as that employed by Haylock and Goodess (2004).

A separate CCA was carried out for each of the 12 rainfall indices with SST. The SST data used were taken from Global Sea Ice Coverage and Sea Surface Temperature (GISST) dataset version 2.3b (Parker et al. $1995)$ over the region $60^{\circ} \mathrm{S}-20^{\circ} \mathrm{N}, 120^{\circ} \mathrm{W}-0^{\circ}$. In order not to unduly weight SST grid points at higher latitudes, the data were first interpolated onto an equal-area grid over the same region of dimensions $280 \mathrm{~km} \times 280 \mathrm{~km}$ at the equator. The rainfall indices were used at the 54 station locations. Although this will give slightly more weight toward regions with higher station density (southern Brazil), it was decided that this was better than either interpolating the stations to a regular grid or thinning the station network. Gridding the 54 stations over the entire continent, even with a very coarse grid 
TABLE 3. Canonical correlation, \% variance, correlation between canonical coefficients and the SOI for each coupled canonical pattern, and the significance of the trend in the indices' canonical coefficients. Probabilities less than 0.05 are deemed significant and are indicated in bold. Totals are indicated in italics.

\begin{tabular}{|c|c|c|c|c|c|c|c|}
\hline Index & Component & $r$ & SST & Index & $r(\mathrm{SST}, \mathrm{SOI})$ & $r($ index, $\mathrm{SOI})$ & $p($ trend $)$ \\
\hline PRCPTOT & 1 & 0.892 & $10.6 \%$ & $15.6 \%$ & 0.748 & 0.655 & 0.62 \\
\hline PRCPTOT & 2 & 0.809 & $26.3 \%$ & $12.2 \%$ & -0.094 & 0.031 & 0.00 \\
\hline \multirow[t]{2}{*}{ PRCPTOT } & 3 & 0.464 & $9.1 \%$ & $11.2 \%$ & -0.191 & -0.204 & 1.00 \\
\hline & Total & & $45.9 \%$ & $39.0 \%$ & & & \\
\hline SDII & 1 & 0.819 & $19.4 \%$ & $12.9 \%$ & 0.669 & 0.482 & 0.00 \\
\hline \multirow[t]{2}{*}{ SDII } & 2 & 0.624 & $25.5 \%$ & $7.3 \%$ & 0.149 & 0.185 & 0.00 \\
\hline & Total & & $44.9 \%$ & $20.2 \%$ & & & \\
\hline CDD & 1 & 0.883 & $27.7 \%$ & $6.7 \%$ & 0.038 & 0.034 & 0.00 \\
\hline CDD & 2 & 0.667 & $5.0 \%$ & $10.6 \%$ & 0.337 & 0.308 & 0.51 \\
\hline CDD & 3 & 0.347 & $12.6 \%$ & $8.4 \%$ & 0.354 & 0.253 & 0.13 \\
\hline \multirow[t]{2}{*}{ CDD } & 4 & 0.243 & $7.2 \%$ & $7.2 \%$ & -0.095 & -0.106 & 0.62 \\
\hline & Total & & $52.5 \%$ & $32.9 \%$ & & & \\
\hline CWD & 1 & 0.595 & $11.4 \%$ & $7.2 \%$ & 0.517 & 0.377 & 0.82 \\
\hline CWD & 2 & 0.505 & $19.6 \%$ & $8.4 \%$ & 0.409 & 0.026 & 0.13 \\
\hline \multirow[t]{2}{*}{ CWD } & 3 & 0.356 & $11.3 \%$ & $7.8 \%$ & 0.162 & 0.145 & 0.35 \\
\hline & Total & & $42.3 \%$ & $23.4 \%$ & & & \\
\hline $\mathrm{R} 10 \mathrm{~mm}$ & 1 & 0.889 & $9.8 \%$ & $12.8 \%$ & -0.751 & -0.649 & 0.61 \\
\hline $\mathrm{R} 10 \mathrm{~mm}$ & 2 & 0.753 & $23.8 \%$ & $12.4 \%$ & -0.077 & 0.022 & 0.00 \\
\hline \multirow[t]{2}{*}{$\mathrm{R} 10 \mathrm{~mm}$} & 3 & 0.493 & $10.6 \%$ & $11.3 \%$ & -0.227 & -0.226 & 0.89 \\
\hline & Total & & $44.1 \%$ & $36.5 \%$ & & & \\
\hline $\mathrm{R} 20 \mathrm{~mm}$ & 1 & 0.876 & $14.7 \%$ & $14.7 \%$ & 0.753 & 0.614 & 0.03 \\
\hline $\mathrm{R} 20 \mathrm{~mm}$ & 2 & 0.831 & $27.3 \%$ & $8.0 \%$ & 0.005 & 0.086 & 0.00 \\
\hline $\mathrm{R} 20 \mathrm{~mm}$ & 3 & 0.583 & $5.4 \%$ & $8.0 \%$ & 0.133 & 0.129 & 0.56 \\
\hline \multirow[t]{2}{*}{$\mathrm{R} 20 \mathrm{~mm}$} & 4 & 0.289 & $6.1 \%$ & $8.6 \%$ & -0.110 & -0.119 & 0.29 \\
\hline & Total & & $53.5 \%$ & $39.3 \%$ & & & \\
\hline R95p & 1 & 0.878 & $16.1 \%$ & $14.3 \%$ & 0.717 & 0.566 & 0.01 \\
\hline \multirow[t]{2}{*}{ R95p } & 2 & 0.395 & $10.9 \%$ & $7.0 \%$ & 0.117 & 0.179 & 0.27 \\
\hline & Total & & $27.0 \%$ & $21.3 \%$ & & & \\
\hline R99p & 1 & 0.869 & $20.2 \%$ & $11.8 \%$ & 0.745 & 0.550 & 0.00 \\
\hline \multirow[t]{2}{*}{ R99p } & 2 & 0.451 & $11.0 \%$ & $7.6 \%$ & 0.140 & 0.038 & 0.07 \\
\hline & Total & & $31.1 \%$ & $19.4 \%$ & & & \\
\hline RX1day & 1 & 0.570 & $10.3 \%$ & $8.4 \%$ & 0.408 & 0.312 & 0.17 \\
\hline \multirow[t]{2}{*}{ RX1day } & 2 & 0.355 & $8.7 \%$ & $9.4 \%$ & 0.373 & 0.081 & 0.74 \\
\hline & Total & & $19.1 \%$ & $17.9 \%$ & & & \\
\hline RX5day & 1 & 0.553 & $16.2 \%$ & $10.4 \%$ & -0.198 & -0.167 & 0.24 \\
\hline RX5day & 2 & 0.510 & $9.5 \%$ & $7.8 \%$ & -0.479 & -0.242 & 0.46 \\
\hline RX5day & 3 & 0.351 & $10.9 \%$ & $8.2 \%$ & 0.009 & 0.101 & 0.11 \\
\hline \multirow[t]{2}{*}{ RX5day } & 4 & 0.133 & $12.1 \%$ & $8.4 \%$ & -0.006 & 0.024 & 0.80 \\
\hline & Total & & $48.7 \%$ & $34.7 \%$ & & & \\
\hline R95pTOT & 1 & 0.773 & $14.1 \%$ & $10.4 \%$ & 0.718 & 0.530 & 0.03 \\
\hline \multirow[t]{2}{*}{ R95pTOT } & 2 & 0.354 & $14.3 \%$ & $6.9 \%$ & 0.242 & 0.246 & 0.07 \\
\hline & Total & & $28.4 \%$ & $17.2 \%$ & & & \\
\hline R99pTOT & 1 & 0.785 & $20.6 \%$ & $9.7 \%$ & 0.761 & 0.516 & 0.00 \\
\hline \multirow[t]{2}{*}{ R99pTOT } & 2 & 0.526 & $10.2 \%$ & $7.7 \%$ & 0.174 & 0.050 & 0.06 \\
\hline & Total & & $30.8 \%$ & $17.4 \%$ & & & \\
\hline
\end{tabular}

spacing, would leave large areas without stations and many grid cells with only one station, thereby negating the point of gridding. Also, with only 54 stations in the network, discarding stations to thin the network to more regular spacing would remove valuable regional information.

There is a chance that the CCA methodology, which optimizes correlation between linear combinations of the two fields, might be biased toward years with un- usually high or low values in the possibly non-Gaussian distributed indices. We therefore performed a CCA using the rank of the indices rather than the indices themselves to reduce the effect of outliers with almost identical results. Since it is easier to interpret the results using the raw indices we have just presented these results.

Table 3 shows statistics of the CCA for each index. The table includes the number of coupled patterns, the 
canonical correlations, the proportion of variance explained by each canonical coefficient for both the SST and rainfall indices, the correlation of the canonical coefficients with the SOI, and the significance of the trend of the indices coefficients.

Seven PCs of SST were used in the CCA (selected by the above Monte Carlo methodology), accounting for $81.4 \%$ of the total SST variance. The objectively determined number of PCs of the indices varied from 2 to 4 PCs. Since this is smaller than the seven PCs of SST used in the CCA, it is the number of PCs of the indices that determines the number of coupled CCA patterns.

Table 3 shows that the canonical coefficients accounted for between $17.2 \%$ and $39.3 \%$ of the total variance in the indices. While this at first seems low, it is an important conclusion that continental-scale variability is still an important factor in interannual variability of extreme rainfall. Since the CCA truncates the number of components of SST from the initial seven, the proportion of variance explained by the SST canonical coefficients varied for each index, between $19.1 \%$ and $53.5 \%$. Generally one would expect variables with a higher spatial coherence to yield significant PCs explaining a higher proportion of the variance. For example, although the SST observations were over a much larger area than the indices, the SST yielded significant PCs accounting for a larger proportion of total variance than any of the rainfall indices. The indices with the highest proportion of variance are the total annual precipitation PRCPTOT (39.0\%) and the two frequency indices-the number of days above $20 \mathrm{~mm}$ R20 $\mathrm{mm}(39.3 \%)$ and the number of days above $10 \mathrm{~mm}$ $\mathrm{R} 10 \mathrm{~mm}(36.5 \%)$. These three indices have at least three significant PCs. The indices with the lowest number of significant PCs and proportion of variance are the two indices reflecting the proportion of total rainfall falling on extreme days R95pTOT $(17.2 \%)$ and R99pTOT $(17.4 \%)$ and the maximum 1-day rainfall RX1day $(17.9 \%)$. These three indices all have two significant PCs.

The maximum canonical correlation varies between the indices from 0.892 for PRCPTOT to 0.553 for RX5day. An examination of the canonical correlations in Table 3 shows no clear relationship between the correlation and the proportion of variance explained by the associated coefficients. For R95p, R99p, RX5day, and R99pTOT the highest canonical correlation is related to the canonical coefficient that explains the highest variance in both SST and the rainfall index. For CDD and RX1day the highest correlation is related to the highest proportion of variance in SST only. For PRCPTOT, SDII, R10 mm, R20 mm, and R95pTOT the highest correlation relates to the coefficient that
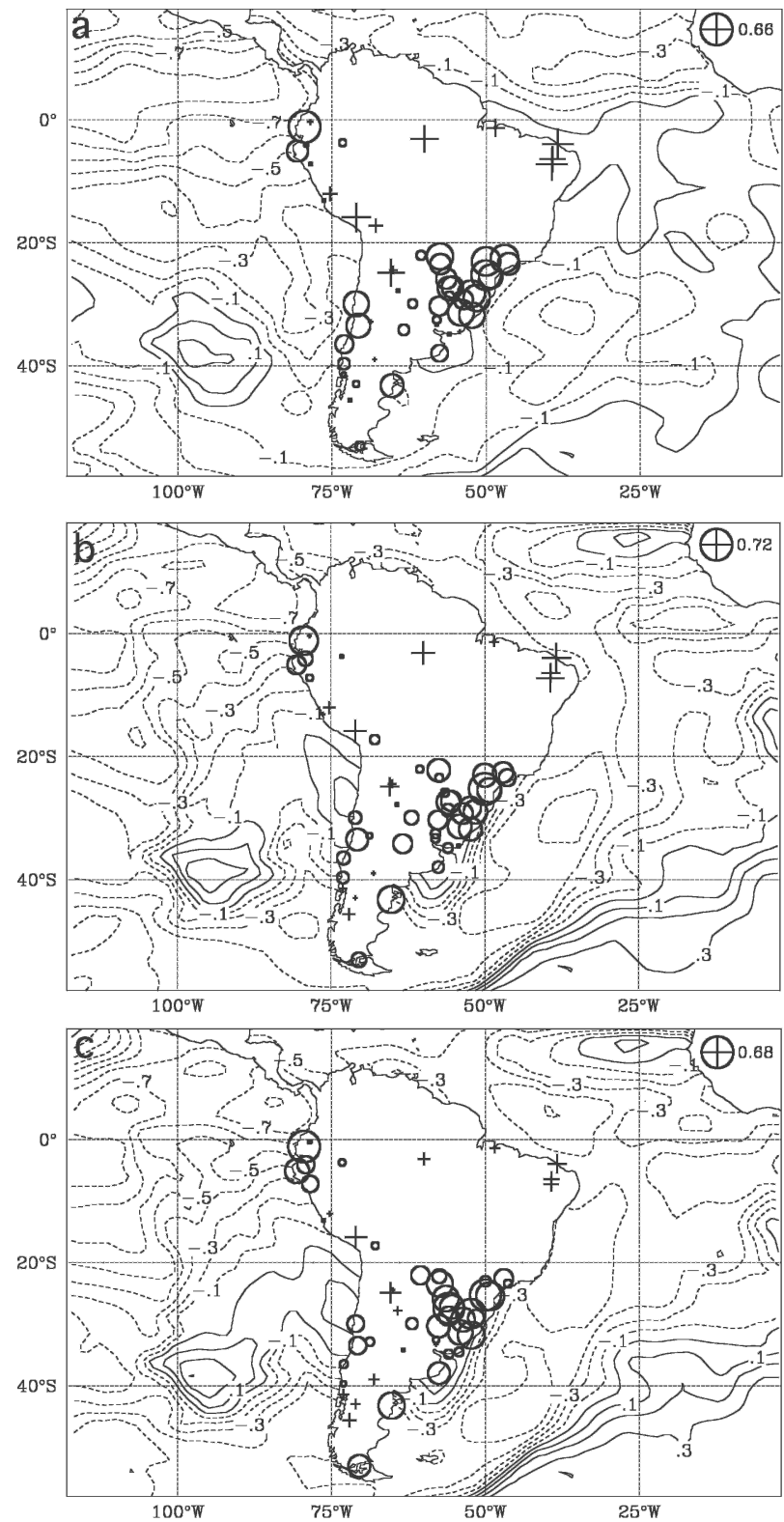

FIG. 5. First CCA patterns for SST with (a) PRCPTOT, (b) R20 $\mathrm{mm}$, and (c) R95p. For the indices, a circle indicates a negative loading and a plus symbol is positive. The size of the symbol is proportional to the magnitude, with the maximum symbol size given in the scale at the top right of each frame.

explains the highest variance in the rainfall index only. For CWD the patterns with the highest correlation explain the highest variance in neither the SST nor the index.

The three coupled patterns that account for the highest proportion of variance in the indices are the first patterns of PRCPTOT, R20 mm, and R95p. Figure 5 shows the factor loadings of the canonical coefficients for the SST and indices for these three cases. The load- 


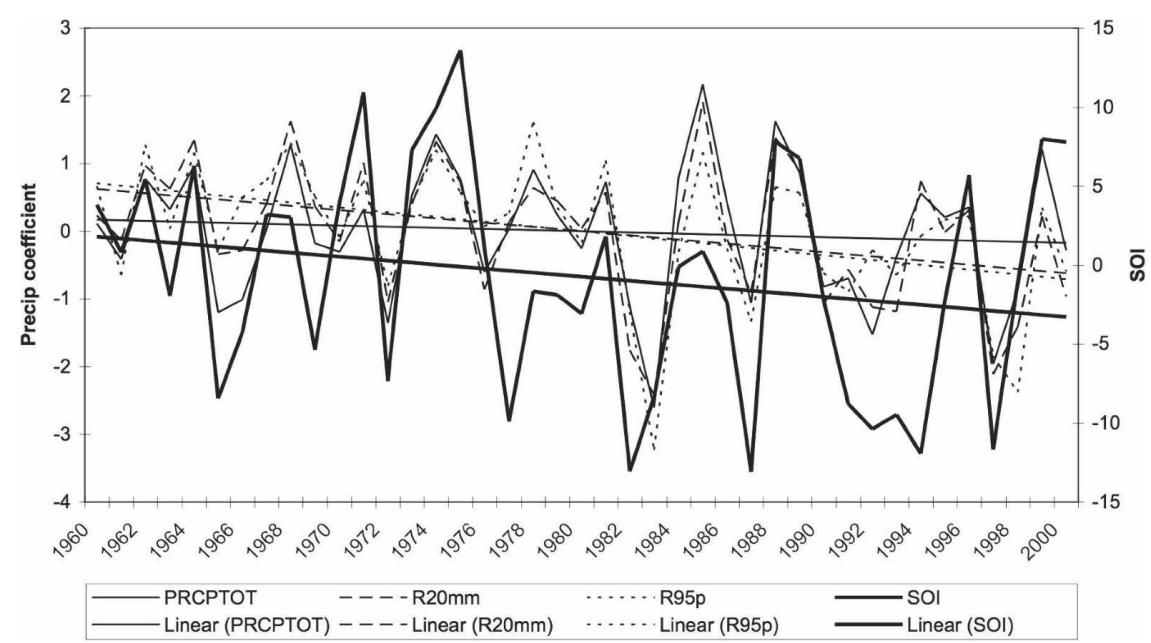

FIG. 6. First canonical coefficient for PRCPTOT, R20 mm, and R95p with the annual SOI.

ings represent the correlations between the canonical coefficients and the SST or indices. The SST patterns in the three panels are very similar and show similarities to the classic ENSO response, for example, the SST composited by the SOI [not shown but see Rasmusson and Carpenter (1982)]. The familiar high loadings in the tropical eastern Pacific and loadings of opposite sign in the southeast Pacific are indicative of ENSO, however the latter are weaker and displaced farther south than observed in other ENSO studies. Also the moderate loadings to the east of the continent as well as those of opposite sign in the South Atlantic are less similar to ENSO. Table 3 shows that the canonical coefficients for these three SST patterns all have a correlation with the annual SOI above 0.7. Of the 12 indices, four do not show a CCA pattern with a strong relationship with ENSO as can be seen by the correlations with the SOI in Table 3. These are the maximum wet and dry spell length indices CWD and CDD and the maximum 1- and 5-day rainfall, RX1day and RX5day. It is interesting to note that these four indices reflect rainfall in a single spell of days whereas all the other indices are indicative of the extremes over the entire year. Therefore one would expect that these four indices would be more sensitive to single anomalous weather patterns possibly not caused by the larger-scale forcing.

Similar patterns of the response of South American rainfall to ENSO have been shown in Dai et al. (1997) and Dai and Wigley (2000) by examining the first principal component of global rainfall.

Figure 6 shows the annual SOI with the first canonical coefficients for PRCPTOT, R20 mm, and R95p, highlighting the matching interannual variability in the SOI and the three indices. The figure also shows that there has been a trend to a more negative SOI and a corresponding trend in the indices, leading to the conclusion that changes in ENSO have contributed to the observed trend in the indices. The trend in the first canonical coefficients for R20 mm and R95p is significant at $p<0.05$, however not for PRCPTOT or the SOI. Since the trend in the rainfall coefficients is negative, the contribution to the trend of the indices from this pattern is opposite to the sign of the loadings in Fig. 5.

The mechanisms for the observed ENSO-related pattern of rainfall changes have been discussed in several of the papers mentioned in the introduction. Marengo (1992) and Marengo and Hastenrath (1993) examined the reason for the variability of rainfall in the Amazon with ENSO. They proposed that during La Niña events in late summer, an anomalously southward-displaced ITCZ caused wetter conditions in the Amazon, with ascending motion over the northern Amazon and associated subsidence and drier conditions west of the Andes in Ecuador and Peru. SST anomalies in the central equatorial Pacific explain less than $40 \%$ of rainfall variance in central Amazonia (Marengo 1992), and the fraction of variance explained by SST anomalies in the central Pacific is slightly higher during the period 197698 compared to 1950-75, as shown by Marengo (2004). This is due the presence of more frequent and intense El Niño events in 1976-98 (with an active role of the tropical Pacific), while during 1950-75 the tropical Pacific was less active. The mechanism and effect of a northward-displaced SACZ during La Niña conditions were examined by Carvalho et al. $(2002,2004)$ and were found to cause the observed decrease in rainfall over the region of southern Brazil and wetter conditions in the north (see also Liebmann et al. 2004b). Both of these patterns are reproduced in our CCA results in Fig. 5. 


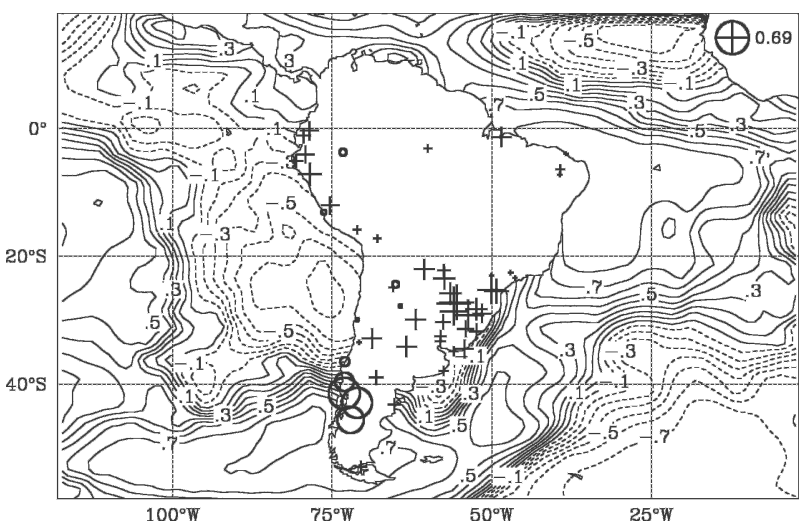

FIG. 7. Same as in Fig. 5, but for the second CCA pattern for SST-PRCPTOT.

To quantify whether any of the other CCA patterns have contributed to the trends in the indices, we calculated the trends in the canonical coefficients (Table 3). Since the units of the normalized canonical coefficients are dimensionless, we have just shown the significance of the trends as given by the probability of the null hypothesis (no trend) being true using a nonparametric Kendall Tau test on the coefficients. Probabilities less than 0.05 are deemed significant and are indicated in bold. This shows that two of the canonical coefficients with strong correlations with the SOI do not have significant trends (PRCPTOT 1 and R10 mm 1). Similarly some of the coefficients with significant trends have small correlations with the SOI (PRCPTOT 2, SDII 2, CDD 1, R10 $\mathrm{mm} \mathrm{2,} \mathrm{and} \mathrm{R20} \mathrm{mm} \mathrm{2).}$

Also, although there is some similarity between the
ENSO-related canonical patterns in Fig. 5 and the trends of the indices in Fig. 2, an important difference is that the stations in southern Chile and southwest Argentina that have seen a significant decrease in many of the indices are not represented by coherent high loadings in Fig. 5. Therefore the patterns in Fig. 5 cannot explain the changes in this region. Figure 7 shows the loading patterns for the second canonical coefficients for PRCPTOT. This pattern of loadings for the rainfall index shows large negative loadings for the stations in the southwest and generally positive loadings elsewhere. Several other stations farther north have negative loadings, but these are of much smaller magnitude. Therefore this pattern represents behavior in the south that is out of phase with the other stations. Interestingly the loading over the southernmost station, Punta Arenas, is small, indicating that this mode is not important for variability at this station.

Figure 8 shows the corresponding canonical coefficients with a strong positive trend in both series, leading to drier conditions in southern Chile and wetter conditions in the rest of the region. The trends in both these series are significant $(p<0.0001)$. Table 3 shows that the correlations between these coefficients and the SOI are low ( -0.094 for the SST and 0.031 for the rainfall). The SST pattern in Fig. 7 is quite complex, showing areas of positive loadings centered west of Patagonia and the tropical South Atlantic along with regions of negative loadings west of the continent, in the tropical North Atlantic, and in the higher latitudes of the South Atlantic. Since the canonical coefficients have a strong positive trend, the areas of positive (negative) SST

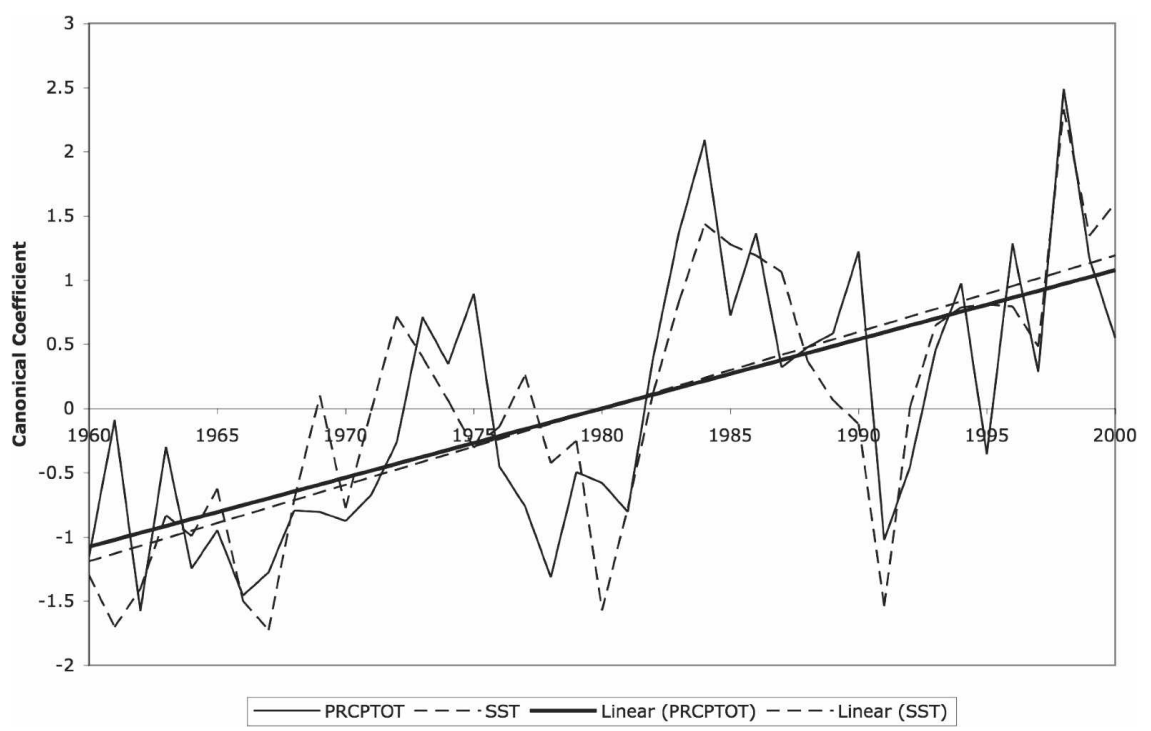

FIG. 8. Second CCA coefficients for SST-PRCPTOT. 
loading are also areas of warming (cooling) with regard to the contribution from this pattern.

To determine the effect of this pattern of SSTs on the circulation we have composited the average annual mean sea level pressure (MSLP) for years when the SST coefficient in Fig. 8 is positive and when it is negative. MSLP was taken from the National Centers for Environmental Prediction-National Center for Atmospheric Research (NCEP-NCAR) reanalyses (Kalnay et al. 1996). These composites are shown in Figs. 9a and $9 \mathrm{~b}$. The figures show the general pattern of low pressure centered over the Amazon Basin, the ridge of the subtropical high at $30^{\circ} \mathrm{S}$ with a trough over the continent, and a steady meridional gradient to lower pressures farther south. Note that the stations in southern Chile and Argentina that have seen a strong decrease in rainfall are situated south of the subtropical high at $40^{\circ}-45^{\circ} \mathrm{S}$. At first the MSLP patterns in Figs. $9 \mathrm{a}$ and $9 \mathrm{~b}$ appear very similar, however, when one considers Fig. $9 \mathrm{c}$, which is the difference of the composite of years with positive SST canonical coefficient minus the negative years (Fig. 9b-9a), significant differences become apparent. In this figure the shaded area shows regions where the difference of the means is significant at $p<$ 0.05 using a $t$ test. The most important features with regard to rainfall over the region are the significant change to higher pressures in the south of the continent and the change to lower pressures in the northeast. In the south the increase in pressure corresponds to a weakening of the trough in Fig. 9b compared with Fig. 9a.

This significant increase in MSLP over the south of the continent suggests that the northward cyclone propagation through South America may be affected, thus confining the rain-bearing systems to higher latitudes. This is supported in Fig. 9c by the significant change to generally lower pressure at the highest latitudes of the region. Recently, Pezza and Ambrizzi (2003) indicated that the total number of Southern Hemisphere cyclones during the austral winter season had declined from 1973 to 1996. On the other hand, they also showed that the number of intense cyclones had increased. Our results suggest that an increase in baroclinic activity at higher latitudes could lead to the confinement of the transient systems to the south, thereby affecting the meridional displacement of polar air masses to South America.

The possibility that the climatological decrease in the number of cyclones over the Southern Hemisphere is linked to climate change has been suggested by several previous studies (e.g., Key and Chan 1999; Simmonds and Keay 2000; Simmonds et al. 1998). Interestingly a similar rainfall decrease has also been found in Austra-
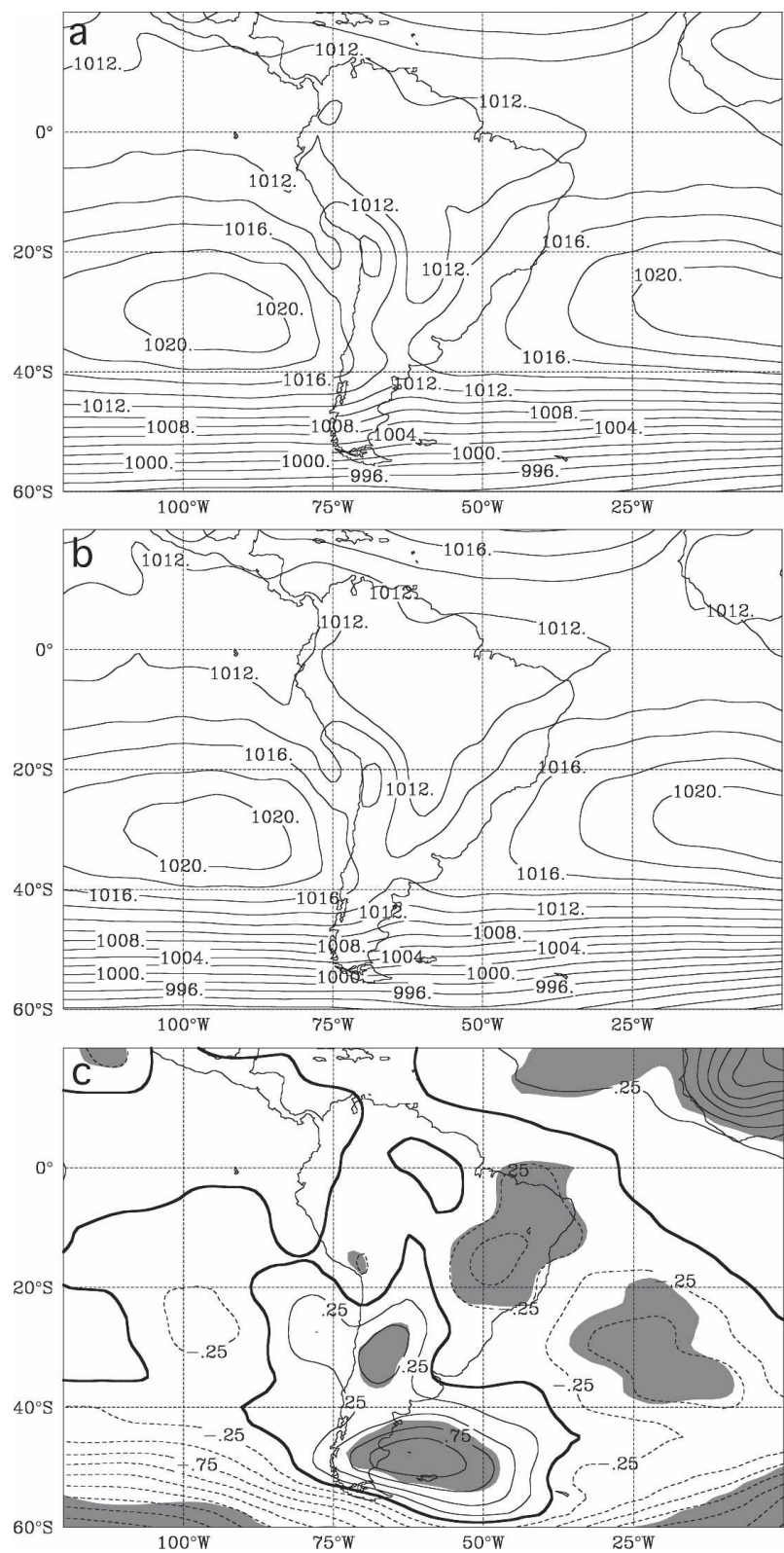

FIG. 9. Annual average MSLP composited for years when (a) second SST-PRCPTOT canonical coefficient $<0$ and (b) second SST-PRCPTOT canonical coefficient $>0$. (c) Difference of (b) (a). Shading shows region where difference is significant at $p<$ 0.05 .

lia in latitudes $30^{\circ}-40^{\circ} \mathrm{S}$ (Allan and Haylock 1993; Smith et al. 2000), being in agreement with the present analysis. This regional pattern is consistent with a hemispheric-scale pattern of increases in pressure in middle latitudes and decreases at high latitudes associated with a trend in the Southern Annular Mode (SAM; Thompson et al. 2000). Modeling and other studies have linked the trend in the SAM and southward shift in the storm 
track to a climate response to decreases in stratospheric ozone (Gillett and Thompson 2003; Sexton 2001; Thompson and Solomon 2002) or as a response to increasing greenhouse gases (Cai et al. 2003; Fyfe 2003; Kushner et al. 2001).

In Fig. 9c there is little change in MSLP over the region of the Patagonian station Punta Arenas, which has seen a significant rainfall increase over the period (Fig. 2). Since the loadings for this station are small for this canonical pattern (Fig. 7), we cannot attribute this rainfall increase to these changes in MSLP. Also this station is located almost directly on the zero contour in Fig. 9c, indicating that this canonical pattern has not lead to any change in pressure at this station, which implyies that there has been no change in the number or intensity of cyclones in the vicinity of this station.

The significant decrease in pressure in northeast Brazil related to this pattern is probably related to the warming in the central Atlantic (Fig. 7). The rainfall stations in this region all have a positive loading, corresponding to wetter conditions due to the significant trend in the canonical coefficients.

Although we have only shown this pattern for PRCPTOT, it is not limited to total rainfall but also to the extremes. A similar CCA pattern, along with canonical coefficients with a strong trend, occurs in some of the indices with significant trends and low SOI correlation (second canonical patterns of R10 mm, R20 mm, and SDII and first pattern of CDD).

The two large-scale changes discussed so far, the changes in ENSO and the weakening of the continental trough, account for most of the regional coupled patterns identified by the CCA for all the indices. Other patterns listed in Table 3 that are not related to one of these two changes either account for a small proportion of total variance of the indices or have a small canonical correlation reflecting a less significant statistical relationship between the SST and rainfall indices. It must be mentioned however that a low proportion of total variance might still indicate a pattern that is important for a particular area, but when considered over the entire region under study is less important.

When performing an analysis like CCA that optimizes linear correlation, there is a chance that any trends in the two datasets will unduly influence the results, leading to coupled patterns that have similar trends but low correlation in interannual variability. Figures 6 and 8 show that this is not the case, with the series having strong similarity in the interannual variability as well as the trends. Still, we checked the results by performing a CCA using detrended data with very similar results.

\section{Detailed analysis for eastern Brazil}

A high density network of daily rainfall stations was available for eastern Brazil and Uruguay from the Global Historical Climatology Network (GHCN) dataset (Vose et al. 1992). We selected from this set of over 6000 stations those that contained no more than 15 days missing for at least $80 \%$ of years 1960-2000. This resulted in 715 stations with sufficient data, with the majority located in the state of São Paulo maintained by the company providing hydroelectricity for the region. Careful quality control, to the degree that was done in section 2, was not possible with such a large set. We therefore first removed all days with rainfall above $1 \mathrm{~mm}$ that appeared after a missing observation, as this rainfall was likely to be an accumulated value. We then examined the time series of the annual total rainfall for each station and compared this with the average of the 10 nearest stations. In this comparison we calculated the ratio of the candidate station to the reference series (average of neighbors) and removed stations that had either a significant trend in this ratio or a significant jump as detected by our homogeneity test (Easterling and Peterson 1995). A trend in this ratio series could indicate a gradual change over time in the exposure of the rain gauge, for example, the growth of surrounding trees, while a jump could indicate a change in the station location, instrumentation, or observer practice. The resulting 354 stations were of sufficient spatial density, especially in the state of São Paulo, for gridding of the indices. We therefore calculated the indices at each station and gridded the annual indices onto a $2^{\circ} \times 2^{\circ}$ grid. To grid the indices we used natural neighbor interpolation (Sibson 1981), a weighted average method that, for each grid point, weights each neighboring station depending on its relative area by constructing a Voronoi diagram.

All stations in this region receive most of their rainfall in the months November-February. We therefore calculated the annual indices over the months JulyJune rather than January-December. This was so as not to split the rainy season, but it also enabled us to determine if the results of sections 3 and 4 were sensitive to the months used.

Figure 10 shows the sign of the trend of the indices as well as those grid points with a significant trend as measured by Kendall's Tau (Kendall 1938). There is a general tendency to wetter conditions in the southwest of the region and drier conditions in the northeast, as typified by PRCPTOT. Grid points in both the region of increase and decrease show significant trends in some of the indices. These results mostly agree with the station analysis (Fig. 2), with the notable exception of 

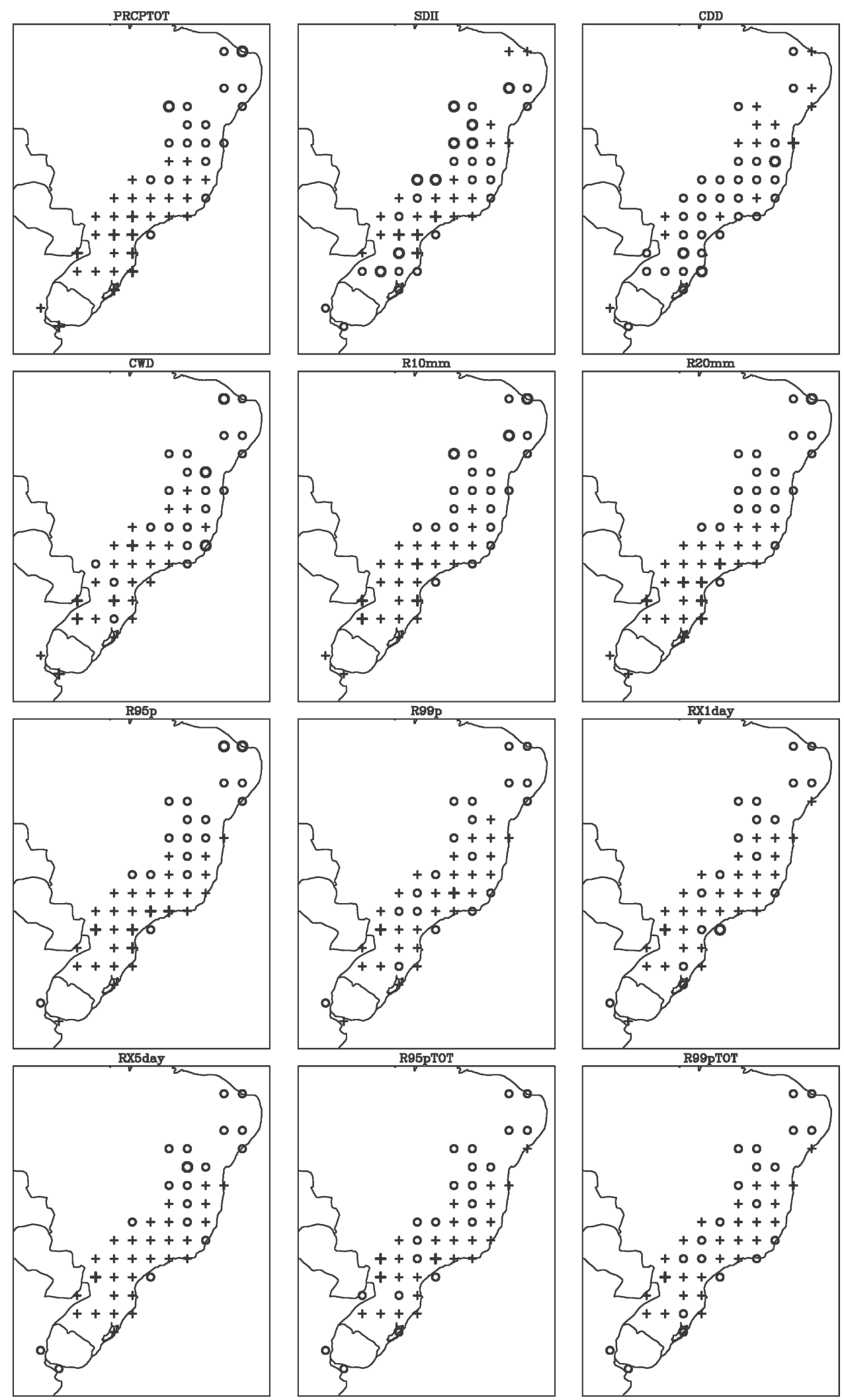

FIG. 10. Sign of the linear trend in gridded rainfall indices as measured by Kendall's Tau. An increase is shown by a plus symbol, a decrease by a circle. Bold values indicate significant at $p<0.05$. 
TABle 4. Same as in Table 3, except for gridded indices.

\begin{tabular}{|c|c|c|c|c|c|c|c|}
\hline Index & Component & $r$ & SST & Index & $r(\mathrm{SST}, \mathrm{SOI})$ & $r$ (index, SOI) & $p$ (trend) \\
\hline PRCPTOT & 1 & 0.770 & $17.7 \%$ & $23.0 \%$ & 0.796 & 0.537 & 0.025 \\
\hline PRCPTOT & 2 & 0.550 & $9.2 \%$ & $16.5 \%$ & 0.312 & 0.190 & 0.805 \\
\hline PRCPTOT & 3 & 0.103 & $\begin{array}{r}7.5 \% \\
34.4 \%\end{array}$ & $\begin{array}{l}12.5 \% \\
52.0 \%\end{array}$ & -0.185 & -0.134 & 0.875 \\
\hline SDII & 1 & 0.748 & $16.6 \%$ & $9.3 \%$ & 0.703 & 0.588 & 0.004 \\
\hline SDII & 2 & 0.675 & $9.4 \%$ & $10.5 \%$ & 0.107 & 0.179 & 0.021 \\
\hline SDII & 3 & 0.292 & $9.1 \%$ & $7.5 \%$ & -0.352 & -0.262 & 0.928 \\
\hline SDII & 4 & 0.193 & $17.0 \%$ & $7.7 \%$ & 0.103 & 0.100 & 0.381 \\
\hline SDII & 5 & 0.112 & $\begin{array}{l}12.3 \% \\
64.4 \%\end{array}$ & $\begin{array}{r}6.5 \% \\
41.5 \%\end{array}$ & -0.386 & 0.001 & 0.621 \\
\hline CDD & 1 & 0.607 & $8.8 \%$ & $14.3 \%$ & 0.592 & 0.249 & 0.193 \\
\hline $\mathrm{CDD}$ & 2 & 0.342 & $20.4 \%$ & $20.2 \%$ & -0.648 & -0.339 & 0.928 \\
\hline $\mathrm{CDD}$ & 3 & 0.137 & $\begin{array}{l}10.0 \% \\
39.1 \%\end{array}$ & $\begin{array}{l}10.5 \% \\
45.0 \%\end{array}$ & 0.069 & 0.105 & 0.419 \\
\hline CWD & 1 & 0.713 & $11.7 \%$ & $8.1 \%$ & 0.582 & 0.428 & 0.005 \\
\hline CWD & 2 & 0.383 & $14.5 \%$ & $8.8 \%$ & -0.359 & -0.228 & 0.928 \\
\hline CWD & 3 & 0.162 & $11.3 \%$ & $15.0 \%$ & -0.412 & -0.264 & 0.053 \\
\hline CWD & 4 & 0.089 & $\begin{array}{l}17.5 \% \\
55.1 \%\end{array}$ & $\begin{array}{r}9.7 \% \\
41.6 \%\end{array}$ & -0.372 & 0.088 & 0.857 \\
\hline $\mathrm{R} 10 \mathrm{~mm}$ & 1 & 0.708 & $17.4 \%$ & $23.5 \%$ & -0.786 & -0.468 & 0.031 \\
\hline $\mathrm{R} 10 \mathrm{~mm}$ & 2 & 0.559 & $9.3 \%$ & $16.9 \%$ & 0.311 & 0.169 & 0.946 \\
\hline $\mathrm{R} 10 \mathrm{~mm}$ & 3 & 0.120 & $\begin{array}{l}11.2 \% \\
37.9 \%\end{array}$ & $\begin{array}{l}10.6 \% \\
51.0 \%\end{array}$ & -0.224 & -0.159 & 0.982 \\
\hline $\mathrm{R} 20 \mathrm{~mm}$ & 1 & 0.764 & $18.5 \%$ & $20.4 \%$ & 0.809 & 0.569 & 0.010 \\
\hline $\mathrm{R} 20 \mathrm{~mm}$ & 2 & 0.515 & $9.2 \%$ & $13.8 \%$ & 0.313 & 0.162 & 0.982 \\
\hline $\mathrm{R} 20 \mathrm{~mm}$ & 3 & 0.136 & $\begin{array}{r}8.4 \% \\
36.2 \%\end{array}$ & $\begin{array}{l}11.8 \% \\
46.0 \%\end{array}$ & -0.165 & -0.152 & 0.686 \\
\hline R95p & 1 & 0.821 & $16.8 \%$ & $14.3 \%$ & 0.811 & 0.619 & 0.009 \\
\hline R95p & 2 & 0.414 & $9.9 \%$ & $10.3 \%$ & 0.338 & 0.198 & 0.445 \\
\hline R95p & 3 & 0.110 & $\begin{array}{r}8.0 \% \\
34.8 \%\end{array}$ & $\begin{array}{l}10.3 \% \\
34.9 \%\end{array}$ & -0.070 & -0.045 & 0.964 \\
\hline R99p & 1 & 0.743 & $15.2 \%$ & $10.7 \%$ & 0.799 & 0.555 & 0.323 \\
\hline R99p & 2 & 0.251 & $\begin{array}{l}15.3 \% \\
30.5 \%\end{array}$ & $\begin{array}{r}8.7 \% \\
19.3 \%\end{array}$ & -0.264 & 0.008 & 0.653 \\
\hline RX1day & 1 & 0.574 & $19.0 \%$ & $8.6 \%$ & 0.808 & 0.401 & 0.037 \\
\hline RX1day & 2 & 0.435 & $\begin{array}{r}8.4 \% \\
27.5 \%\end{array}$ & $\begin{array}{r}8.8 \% \\
17.4 \%\end{array}$ & -0.062 & 0.146 & 0.432 \\
\hline RX5day & 1 & 0.764 & $17.2 \%$ & $9.3 \%$ & -0.682 & -0.429 & 0.013 \\
\hline RX5day & 2 & 0.459 & $9.9 \%$ & $10.2 \%$ & -0.455 & -0.281 & 1.000 \\
\hline RX5day & 3 & 0.066 & $\begin{array}{l}11.9 \% \\
39.1 \%\end{array}$ & $\begin{array}{l}10.9 \% \\
30.5 \%\end{array}$ & -0.087 & -0.129 & 0.928 \\
\hline R95pTOT & 1 & 0.722 & $18.9 \%$ & $9.1 \%$ & 0.833 & 0.594 & 0.076 \\
\hline R95pTOT & 2 & 0.402 & $5.9 \%$ & $8.1 \%$ & -0.099 & -0.164 & 0.217 \\
\hline R95pTOT & 3 & 0.105 & $\begin{array}{r}9.1 \% \\
33.9 \%\end{array}$ & $\begin{array}{r}9.5 \% \\
26.7 \%\end{array}$ & 0.288 & 0.053 & 0.653 \\
\hline R99pTOT & 1 & 0.462 & $18.1 \%$ & $8.7 \%$ & 0.794 & 0.356 & 0.770 \\
\hline R99pTOT & 2 & 0.169 & $\begin{array}{l}22.2 \% \\
40.3 \%\end{array}$ & $\begin{array}{r}7.8 \% \\
16.5 \%\end{array}$ & -0.107 & 0.122 & 0.590 \\
\hline
\end{tabular}

SDII, which shows an increase in southern Brazil in Fig. 2 but shows a decrease in the gridded data at six of the grid points, with two of the six being significant. This is unusual since all the other indices show that total and extreme rainfall has increased in this region. This suggests that there has been a larger increase in the number of days with low rainfall than high rainfall, thus leading to a decline in the average rainfall on wet days.
This is supported by the observed increase in the maximum number of consecutive wet days and a decrease in consecutive dry days.

We repeated the CCA of the gridded indices with SST using the same methodology as in section 4 but using SST averaged from July-June to match the period over which the indices were calculated. The number of significant PCs of the indices used in the CCA was 


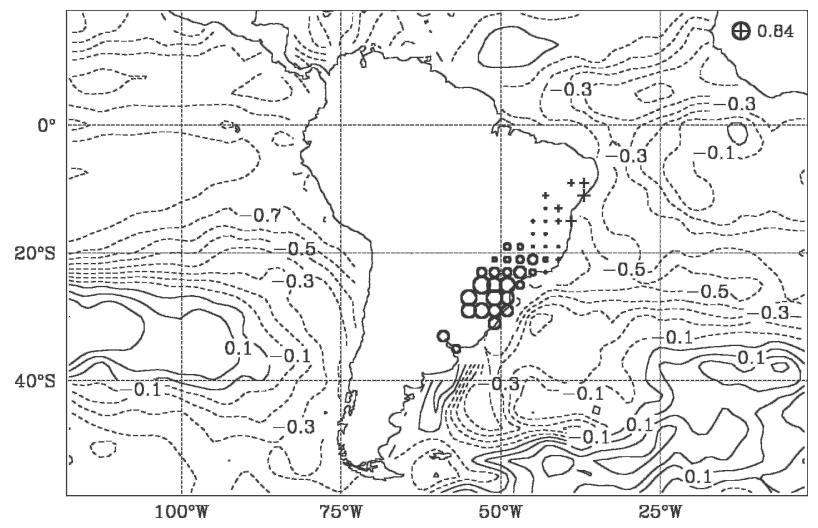

FIG. 11. Same as in Fig. 5, but for the first CCA pattern for SST-R20 mm using gridded Brazilian indices.

different than for the stations, as determined by our objective methodology (section 4). This was within one of the number chosen for the stations with the exception of SDII, for which five were selected, compared with two for the stations. In most cases, the proportion of variance explained by the significant PCs was higher than for the stations, in the range of $16.5 \%$ to $52.0 \%$ compared with $17.2 \%$ to $39.3 \%$ for the stations. For two of the indices, PRCPTOT and R10 mm, more than half of the variance can be explained by the leading PCs. One would expect this to be higher than for the analysis of the stations as the gridded data represent areaaveraged rainfall over a smaller region, which we would expect to be more spatially coherent.

The results of the CCA are shown in Table 4. The three coupled patterns that explain the highest proportion of variance in the indices are the first patterns of PRCPTOT, R10 mm, and R20 mm, all of which represent more than $20 \%$ of the variance of these indices. The correlations between the SOI and SST patterns corresponding to these components are all above 0.78 , and the indices' canonical coefficients have a significant trend. The canonical patterns (e.g., R20 mm; Fig. 11) show loadings of opposite sign in the northeast and southwest regions. As with the station analysis (section 4), this implies that changes in ENSO have contributed to the observed trends in the indices. Correlations with the SOI greater than 0.5 are apparent in the rainfall canonical coefficients for the first coupled patterns of 6 of the 12 indices. The leading canonical patterns for the remaining six indices have strong correlations between the SST component and the SOI, however, the correlations with the rainfall coefficients are lower. This, together with a lower canonical correlation, implies a weaker relationship between SST and these indices.

For all the coupled SST-indices patterns, the only pattern with a significant trend in the rainfall canonical coefficient that does not have a strong correlation with the Southern Oscillation index (SOI) is the second pattern of SDII. The canonical patterns for this component are shown in Fig. 12 with the canonical coefficients in Fig. 13. Although the canonical coefficients have a significant positive trend over the period 1960-2000, Fig. 13 suggests that the trend is part of a low-frequency component to the series, which has decreased in the latter part of the period. Interestingly, the highest magnitude rainfall loadings are the negative loadings over the region in southern Brazil that has seen the previously noted decrease in SDII that was not shown in the station analysis. The associated SST pattern shows positive loadings in midlatitudes that are out of phase with the negative loadings at low latitudes.

The second CCA patterns for PRCPTOT, R10 mm, and R20 $\mathrm{mm}$ are all highly correlated $(>0.95)$, are without a significant trend $(p<0.8)$, and explain a moderately large proportion of the variance of the indices $(>13.8 \%)$. The second canonical pattern for PRCPTOT (Fig. 14) shows rainfall loadings of the same sign over the central part of the region with an SST pattern dominated by loadings of opposing sign in the Central and South Atlantic. With canonical correlations for this pattern less than 0.6, the SST-rainfall connection is not as strong as the ENSO-related patterns. Therefore concluding possible dynamical relationships between the SST and rainfall patterns is difficult. A composite of MSLP depending on the sign of the rainfall canonical coefficient shows no significant difference over the entire continent. Very similar results hold for the second CCA patterns for $\mathrm{R} 10 \mathrm{~mm}$ and $\mathrm{R} 20 \mathrm{~mm}$.

The above discussion explains the important patterns in Table 4. The remaining patterns all have low canonical correlations $(<0.5)$ and hence weak connections between the rainfall indices and SST. We have used the same SST region in both the continental station analysis

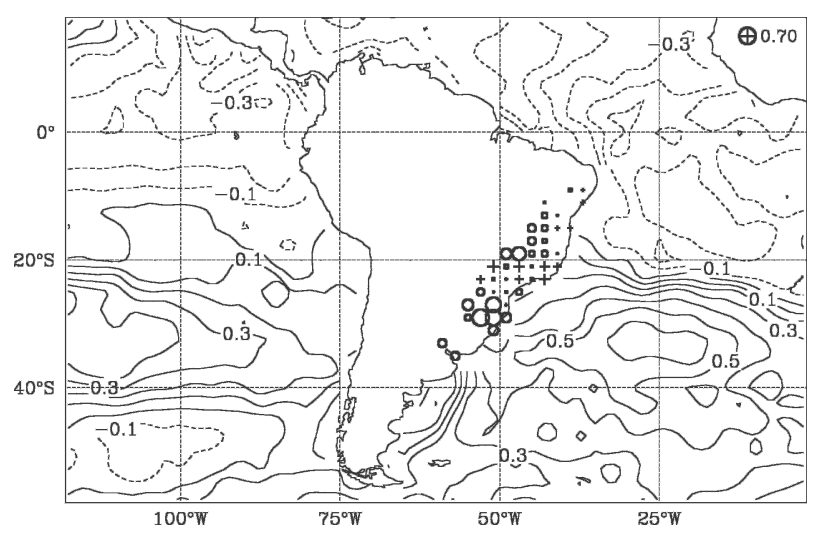

FIG. 12. Same as in Fig. 5, but for the second CCA pattern for SST-SDII using gridded Brazilian indices. 


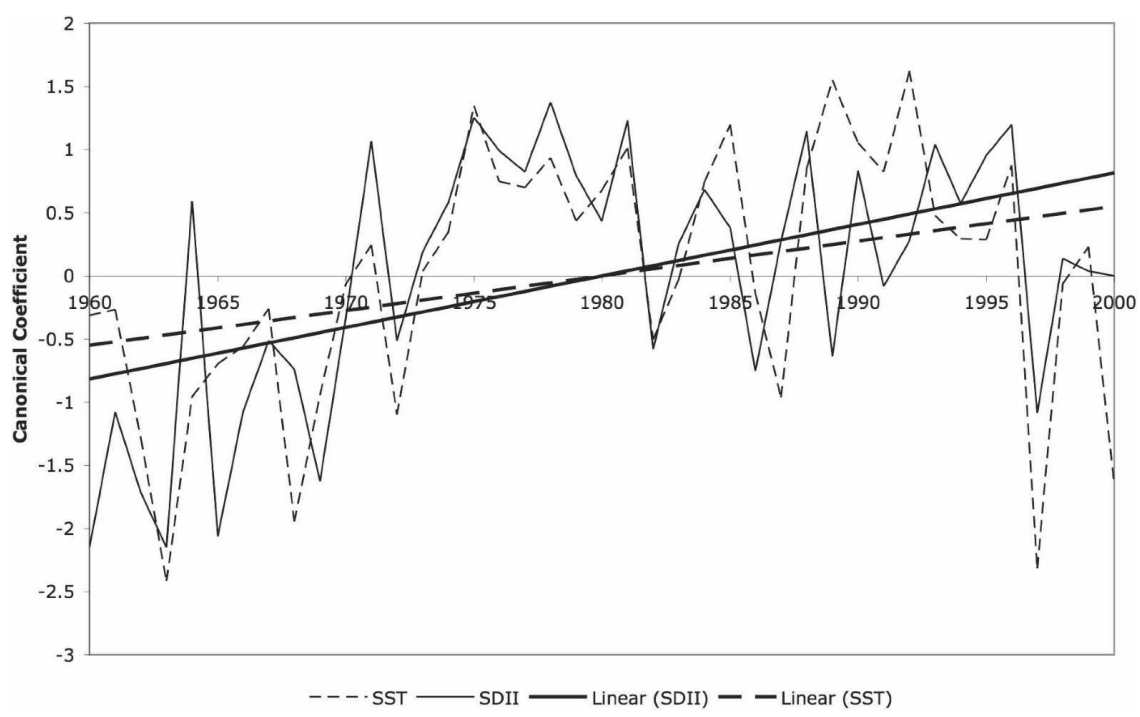

FIG. 13. Second CCA coefficients for SST-SDII using gridded Brazilian indices.

(section 4) and the eastern Brazil gridded analysis. For the Brazilian analysis we also tried a CCA with SSTs over just the surrounding Atlantic Ocean to see if more localized SST-rainfall relationships were revealed that were being obscured when using the larger region. This resulted in coupled patterns that explained less rainfall variance than for the larger SST region with lower canonical correlations implying a weaker SST-rainfall relationship. This confirms that the Pacific, in particular ENSO, is very important in modulating rainfall in eastern Brazil, as has been revealed by many of the studies mentioned in the introduction.

\section{Conclusions}

This study presented results from a weeklong workshop attended by 28 scientists from southern South America. This is a region that was identified by the CC1/CLIVAR Expert Team on Climate Change Monitoring Detection and Indices as lacking in coherent regional studies of long-term trends in climate extremes. The regional analysis, covering a large part of continental South America, was made possible through the workshop format. It showed that valuable results of changes in climate extremes could be obtained using a

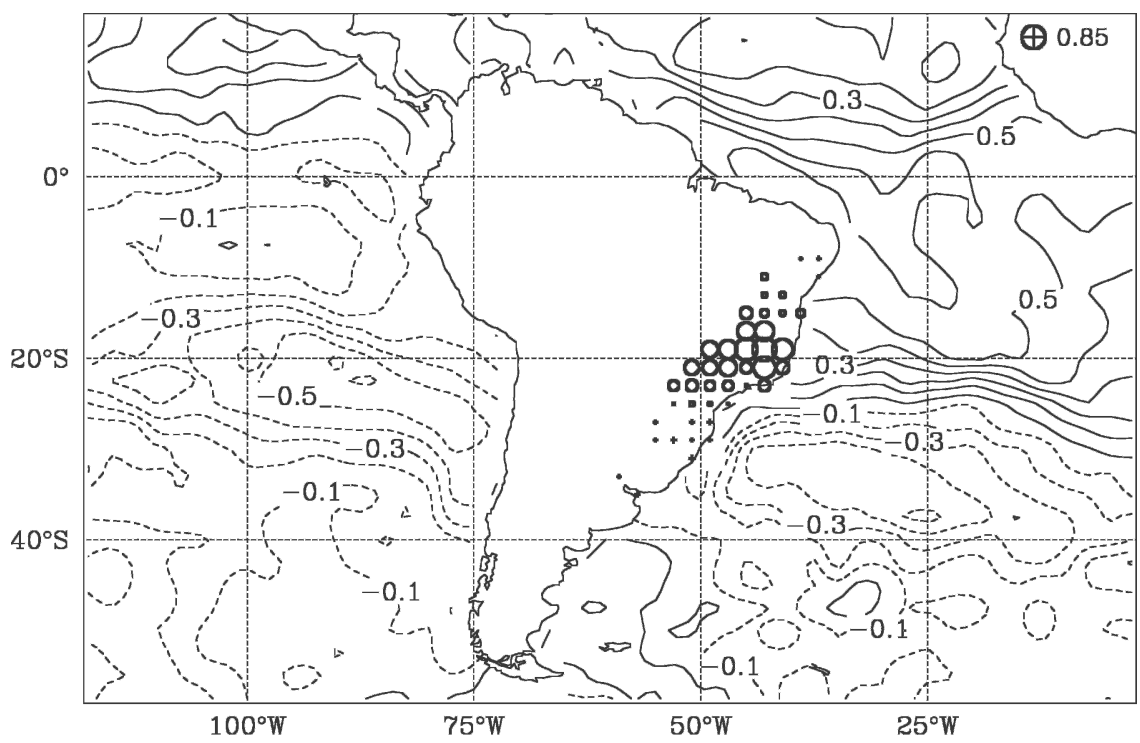

FIG. 14. Same as in Fig. 5, but for the second CCA pattern for SST-PRCPTOT using gridded Brazilian indices. 
consistent methodology, but without individual countries having to surrender potentially commercially valuable daily data.

This paper presents results on trends and variability of 12 annual rainfall indices, covering changes in both the entire distribution as well as its wet and dry extremes. Fifty-four stations were deemed to be of sufficiently high quality and to have sufficient observations to be used to assess changes for the period 1960-2000.

Maps of trends in the 12 rainfall indices showed large regions of coherent change, with many stations showing statistically significant changes in some of the indices. The pattern of trends for the extremes was generally the same as that for total annual rainfall, with a change to wetter conditions in Ecuador and northern Peru and the region of southern Brazil, Paraguay, Uruguay, and northern and central Argentina. A decrease was observed in southern Peru and southern Chile, with the latter showing significant decreases in many indices.

To investigate the possible causes of these spatially coherent trends, we performed a CCA of each of the indices with annually averaged SST observations. This revealed two large-scale coupled patterns that we proposed have contributed to the rainfall changes. The first was a change during the period to more El Niño dominated conditions with a generally lower SOI. Through various previously documented mechanisms, such as increased subsidence and a northward-shifted ITCZ over northeast Brazil and the Amazon Basin and a southeast shift in the SACZ, this was shown to have partly caused the observed trend in the rainfall indices. The changes in ENSO could not account for the significant decrease over southern Chile. A separate CCA mode, uncorrelated with ENSO, suggested that this was caused by a general weakening of the continental trough at higher latitudes, causing a southward shift in the storm tracks during the period. Both of these large-scale SST signals were represented by canonical coefficients with statistically significant trends, which have contributed to the observed significant changes in the rainfall indices.

A similar analysis was carried out for eastern Brazil using gridded indices calculated from 354 stations from the GHCN database. The observed trend toward wetter conditions in the southwest and drier conditions in the northeast could again be explained by changes in ENSO.

While the workshop provided the mechanism to produce a regional study, it also provided the means to build a strong scientific network in the region. These published results, while presenting a valid and statistically sound picture, still only represent a small selection of stations from a vast region. We hope that this will only improve with time.
Acknowledgments. Participation at the workshop by J. R. Abreu de Sousa, G. C. Miranda, L. Molion, E. Ramirez, J. I. Barbosa de Brito, R. Jaildo dos Anjos, P. R. Meira, and G. Ontaneda was greatly appreciated. Support for the workshop was provided by the U.S. Department of State and the Inter American Institute for Global Change Research.

\section{REFERENCES}

Aceituno, P., 1988: On the functioning of the Southern Oscillation in the South American sector. Part I: Surface climate. Mon. Wea. Rev., 116, 505-524.

Allan, R. J., and M. R. Haylock, 1993: Circulation features associated with the winter rainfall decrease in southwestern Australia. J. Climate, 6, 1356-1367.

Barros, V., M. E. Casteñeda, and M. Doyle, 2000: Recent precipitation trends in southern South America east of the Andes: An indication of climatic variability. Southern Hemisphere Paleo and Neo-Climates, P. P. Smolka and W. Volkheimer, Eds., Springer-Verlag, 187-206.

Benestad, R. E., and A. Melsom, 2002: Is there a link between the unusually wet autumns in southeastern Norway and seasurface temperature anomalies? Climate Res., 23, 67-79.

Bretherton, C. S., C. Smith, and J. M. Wallace, 1992: An intercomparison of methods for finding coupled patterns in climate data. J. Climate, 5, 541-560.

Brunetti, M., M. Maugeri, T. Nanni, and A. Navarra, 2002: Droughts and extreme events in regional daily Italian precipitation series. Int. J. Climatol., 22, 543-558.

Cai, W. J., P. H. Whetton, and D. J. Karoly, 2003: The response of the Antarctic Oscillation to increasing and stabilized atmospheric $\mathrm{CO}_{2}$. J. Climate, 16, 1525-1538.

Carvalho, L. M. V., C. Jones, and B. Liebmann, 2002: Extreme precipitation events in southeastern South America and large-scale convective patterns in the South Atlantic convergence zone. J. Climate, 15, 2377-2394.

- ——, and — 2004: The South Atlantic convergence zone: Intensity, form, persistence, and relationships with intraseasonal to interannual activity and extreme rainfall. J. Climate, 17, 88-108.

Chen, T. C., J. H. Yoon, K. J. St Croix, and E. S. Takle, 2001: Suppressing impacts of the Amazonian deforestation by the global circulation change. Bull. Amer. Meteor. Soc., 82, 22092216.

Chu, P.-S., Z.-P. Yu, and S. Hastenrath, 1994: Detecting climate change concurrent with deforestation in the Amazon BasinWhich way has it gone? Bull. Amer. Meteor. Soc., 75, 579583.

Dai, A. G., and T. M. L. Wigley, 2000: Global patterns of ENSOinduced precipitation. Geophys. Res. Lett., 27, 1283-1286.

—, I. Y. Fung, and A. D. Del Genio, 1997: Surface observed global land precipitation variations during 1900-88. J. Climate, 10, 2943-2962.

Depaiva, E. M. C. D., and R. T. Clarke, 1995: Time trends in rainfall records in Amazonia. Bull. Amer. Meteor. Soc., 76, 2203-2209.

Doyle, M. E., and V. R. Barros, 2002: Midsummer low-level circulation and precipitation in subtropical South America and related sea surface temperature anomalies in the South Atlantic. J. Climate, 15, 3394-3410.

Easterling, D. R., and T. C. Peterson, 1995: A new method for 
detecting undocumented discontinuities in climatological time-series. Int. J. Climatol., 15, 369-377.

- L. L. Alexander, A. Mokssit, and V. Detemmerman, 2003: CC1/CLIVAR workshop to develop priority climate indices. Bull. Amer. Meteor. Soc., 84, 1403-1407.

Folland, C. K., and Coauthors, 1999: Workshop on Indices and Indicators for Climate Extremes, Asheville, NC, USA, 3-6 June 1997-Breakout Group C: Temperature indices for climate extremes. Climate Change, 42, 31-43.

Frei, C., and C. Schar, 2001: Detection probability of trends in rare events: Theory and application to heavy precipitation in the Alpine region. J. Climate, 14, 1568-1584.

Frich, P., L. V. Alexander, P. Della-Marta, B. Gleason, M. Haylock, A. M. G. K. Tank, and T. Peterson, 2002: Observed coherent changes in climatic extremes during the second half of the twentieth century. Climate Res., 19, 193-212.

Fyfe, J. C., 2003: Extratropical Southern Hemisphere cyclones: Harbingers of climate change? J. Climate, 16, 2802-2805.

Gentry, A. H., and J. Lopez-Parodi, 1980: Deforestation and increased flooding of the upper Amazon. Science, 210, 13541356.

Gillett, N. P., and D. W. J. Thompson, 2003: Simulation of recent Southern Hemisphere climate change. Science, 302, 273-275.

Grimm, A. G., and I. Pscheidt, 2001: Atmospheric patterns associated with extreme rainfall events in the spring during El Niño, La Niña and neutral years in southern Brazil (in Portuguese). Proc. Ninth Congress of the Latin-American and Iberian Federation of Meteorological Societies and Eighth Argentinean Congress of Meteorology, Buenos Aires, Argentina, Centro Argentino de Meteorólogos e Federção LatinoAmericana e Ibérica de Sociedades de Meteorologia, CDROM.

Grimm, A. M., 2003: The El Niño impact on the summer monsoon in Brazil: Regional processes versus remote influences. J. Climate, 16, 263-280.

_ 2004: How do La Niña events disturb the summer monsoon system in Brazil? Climate Dyn., 22, 123-138.

_ S. E. T. Ferraz, and J. Gomes, 1998: Precipitation anomalies in southern Brazil associated with El Niño and La Niña events. J. Climate, 11, 2863-2880.

— , V. R. Barros, and M. E. Doyle, 2000: Climate variability in southern South America associated with El Niño and La Niña events. J. Climate, 13, 35-58.

Groisman, P. Y., and Coauthors, 1999: Changes in the probability of heavy precipitation: Important indicators of climatic change. Climate Change, 42, 243-283.

Hastenrath, S., and L. Greischar, 1993: Further work on the prediction of northeast Brazil rainfall anomalies. J. Climate, 6, 743-758.

Haylock, M., and N. Nicholls, 2000: Trends in extreme rainfall indices for an updated high quality data set for Australia, 1910-1998. Int. J. Climatol., 20, 1533-1541.

_ extreme winter rainfall and links with mean large-scale circulation. Int. J. Climatol., 24, 759-776.

Hennessy, K. J., R. Suppiah, and C. M. Page, 1999: Australian rainfall changes, 1910-1995. Aust. Meteor. Mag., 48, 1-13.

Kalnay, E., and Coauthors, 1996: The NCEP/NCAR 40-Year Reanalysis Project. Bull. Amer. Meteor. Soc., 77, 437-471.

Karl, T. R., and R. W. Knight, 1998: Secular trends of precipitation amount, frequency, and intensity in the United States. Bull. Amer. Meteor. Soc., 79, 231-241.
Kendall, M. G., 1938: A new measure of rank correlation. Biometrika, 30, 81-93.

Key, J. R., and A. C. K. Chan, 1999: Multidecadal global and regional trends in $1000 \mathrm{mb}$ and $500 \mathrm{mb}$ cyclone frequencies. Geophys. Res. Lett., 26, 2053-2056.

Klein Tank, A. M. G. K., and G. P. Konnen, 2003: Trends in indices of daily temperature and precipitation extremes in Europe, 1946-99. J. Climate, 16, 3665-3680.

Kushner, P. J., I. M. Held, and T. L. Delworth, 2001: Southern Hemisphere atmospheric circulation response to global warming. J. Climate, 14, 2238-2249.

Liebmann, B., G. N. Kiladis, J. A. Marengo, T. Ambrizzi, and J. D. Glick, 1999: Submonthly convective variability over South America and the South Atlantic convergence zone. $J$. Climate, 12, 1877-1891.

,-- C. S. Vera, A. C. Saulo, and L. M. V. Carvalho, 2004a: Subseasonal variations of rainfall in South America in the vicinity of the low-level jet east of the Andes and comparison to those in the South Atlantic convergence zone. J. Climate, 17, 3829-3842.

— , C. S. Vera, L. M. V. Carvalho, I. Camilloni, M. P. Hoerling, V. R. Barros, J. Báez, and M. Bidegain, 2004b: An observed trend in central South American precipitation. J. Climate, 17, 4357-4367.

Manton, M. J., and N. Nicholls, 1999: Monitoring trends in extreme climate events. APN Newsletter, Vol. 5, No. 1, 1-3.

— , and Coauthors, 2001: Trends in extreme daily rainfall and temperature in Southeast Asia and the South Pacific: 19611998. Int. J. Climatol., 21, 269-284.

Marengo, J. A., 1992: Interannual variability of surface climate in the Amazon basin. Int. J. Climatol., 12, 853-863. , 2004: Interdecadal variability and trends of rainfall across the Amazon basin. Theor. Appl. Climatol., 78, 79-96.

, and S. Hastenrath, 1993: Case studies of extreme climatic events in the Amazon basin. J. Climate, 6, 617-627.

_ J. Tomasella, and C. R. Uvo, 1998: Trends in streamflow and rainfall in tropical South America: Amazonia, eastern Brazil, and northwestern Peru. J. Geophys. Res., 103D, 1775-1783.

_ B. Liebmann, V. E. Kousky, N. P. Filizola, and I. C. Wainer, 2001: Onset and end of the rainy season in the Brazilian Amazon Basin. J. Climate, 14, 833-852.

_ W. R. Soares, C. Saulo, and M. Nicolini, 2004: Climatology of the low-level jet east of the Andes as derived from the NCEP-NCAR reanalyses: Characteristics and temporal variability. J. Climate, 17, 2261-2280.

Matsuyama, H., J. A. Marengo, G. O. Obregon, and C. A. Nobre, 2002: Spatial and temporal variabilities of rainfall in tropical South America as derived from Climate Prediction Center merged analysis of precipitation. Int. J. Climatol., 22, 175195.

Minetti, J. L., 1998: Trends and jumps in the annual precipitation in South America, south of the 15 degrees S. Atmosfera, 11, 205-221.

_ W. M. Vargas, A. G. Poblete, L. R. Acuna, and G. Casagrande, 2003: Non-linear trends and low frequency oscillations in annual precipitation over Argentina and Chile, 19311999. Atmosfera, 16, 119-135.

Nicholls, N., and W. Murray, 1999: Workshop on Indices and Indicators for Climate Extremes, Asheville, NC, USA, 3-6 June 1997-Breakout Group B: Precipitation. Climate Change, 42, 23-29.

, G. V. Gruza, J. Jonzel, T. R. Karl, L. A. Ogallo, and D. E. Parker, 1996: Observed climate variability and change. Cli- 
mate Change 1995, J. T. Houghton et al., Eds., Cambridge University Press, 133-192.

Nogues-Paegle, J., and Coauthors, 2002: Progress in Pan American CLIVAR research: Understanding the South American Monsoon. Meteorologica, 27, 1-30.

Osborn, T. J., M. Hulme, P. D. Jones, and T. A. Basnett, 2000: Observed trends in the daily intensity of United Kingdom precipitation. Int. J. Climatol., 20, 347-364.

Parker, D. E., E. Jackson, and E. B. Horton, 1995: The 1961-1990 GISST2.2 sea surface temperature and sea-ice climatology. Climate Research Tech. Note 63, Hadley Centre for Climate Prediction and Research, $42 \mathrm{pp}$.

Peterson, T. C., and Coauthors, 2002: Recent changes in climate extremes in the Caribbean region. J. Geophys. Res., 107, 4601, doi:10.1029/2002JD002251.

Pezza, A. B., and T. Ambrizzi, 2003: Variability of Southern Hemisphere cyclone and anticyclone behavior: Further analysis. J. Climate, 16, 1075-1083.

Plummer, N., and Coauthors, 1999: Changes in climate extremes over the Australian region and New Zealand during the twentieth century. Climate Change, 42, 183-202.

Preisendorfer, R. W., F. W. Zwiers, and T. P. Barnett, 1981: Foundations of Principal Component Selection Rules. SIO Reference Series 81-4, Scripps Institution of Oceanography, 192 pp.

Press, W. H., B. P. Flannery, S. A. Teukolsky, and W. T. Vetterling, 1986: Numerical Recipes: The Art of Scientific Computing. Cambridge University Press, $818 \mathrm{pp}$.

Rasmusson, E. M., and T. H. Carpenter, 1982: Variations in tropical sea surface temperature and surface wind fields associated with the Southern Oscillation/El Niño. Mon. Wea. Rev., 110, 354-384.

Rogers, J. C., 1988: Precipitation variability over the Caribbean and tropical Americas associated with the Southern Oscillation. J. Climate, 1, 172-182.

Ropelewski, C. F., and M. S. Halpert, 1987: Global and regional scale precipitation patterns associated with the El Niño/ Southern Oscillation. Mon. Wea. Rev., 115, 1606-1626.

— and 1989: Precipitation patterns associated with the high index phase of the Southern Oscillation. J. Climate, 2 , 268-284.

Rusticucci, M., and O. Penalba, 2000: Interdecadal changes in the precipitation seasonal cycle over Southern South America and their relationship with surface temperature. Climate Res., 16, 1-15.
Sexton, D. M. H., 2001: The effect of stratospheric ozone depletion on the phase of the Antarctic Oscillation. Geophys. Res. Lett., 28, 3697-3700.

Sibson, R., 1981: A brief description of natural neighbor interpolation. Interpreting Multivariate Data, V. Barnett, Ed., John Wiley \& Sons, 21-36.

Simmonds, I., and K. Keay, 2000: Variability of Southern Hemisphere extratropical cyclone behavior, 1958-97. J. Climate, 13, 550-561.

, D. A. Jones, and D. J. Walland, 1998: Multi-decadal climate variability in the Antarctic region and global change. Ann. Glaciol., 27, 617-622.

Smith, I. N., P. McIntosh, T. J. Ansell, C. J. C. Reason, and K. McInnes, 2000: Southwest Western Australian winter rainfall and its association with Indian Ocean climate variability. Int. J. Climatol., 20, 1913-1930.

Thompson, D. W. J., and S. Solomon, 2002: Interpretation of recent Southern Hemisphere climate change. Science, 296, 895-899.

_ J. M. Wallace, and G. C. Hegerl, 2000: Annular modes in the extratropical circulation. Part II: Trends. J. Climate, 13, 10181036.

Vaes, G., P. Willems, and J. Berlamont, 2002: 100 years of Belgian rainfall: Are there trends? Water Sci. Technol., 45, 55-61.

Vera, C., and Coauthors, 2006: Toward a unified view of the American monsoon systems. J. Climate, in press.

Vincent, L. A., and Coauthors, 2005: Observed trends in indices of daily temperature extremes in South America 1960-2000. J. Climate, 18, 5011-5023.

Viney, N. R., and B. C. Bates, 2004: It never rains on Sunday: The prevalence and implications of untagged multi-day rainfall accumulations in the Australian high quality data set. Int. J. Climatol., 24, 1171-1192.

Vose, R. S., R. L. Schmoyer, P. M. Steurer, T. C. Peterson, R. Heim, T. R. Karl, and J. K. Eischeid, 1992: The Global Historical Climatology Network: Long-term monthly temperature, precipitation, sea level pressure, and station pressure data. ORNL/CDIAC-53, NDP-041, Carbon Dioxide Information Analysis Center, Oak Ridge National Laboratory, $324 \mathrm{pp}$.

Zhang, X., G. Hegerl, F. W. Zwiers, and J. Kenyon, 2005: Avoiding inhomogeneity in percentile-based indices of temperature extremes. J. Climate, 18, 1641-1651. 